


\section{U. S. ARMY RESEARCH INSTITUTE FOR THE BEHAVIORAL AND SOCIAL SCIENCES}
A Field Operating Agency under the Jurisdiction of the Deputy Chief of Staff for Personnel

EDGAR M. JOHNSON

Technical Director
WM. DARRYL HENDERSON

COL, IN

Commanding

Research accomplished under contract

for the Department of the Army

Klein Associates

Technical review by

D. MacPherson

S. Sabat

Norices

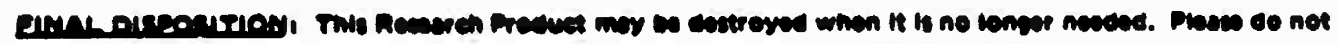

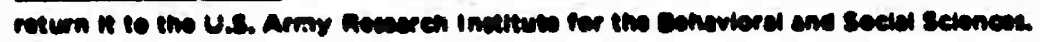

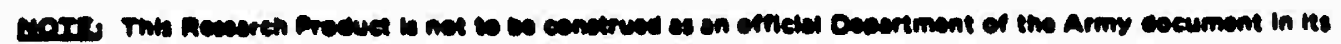
erecone rearn. 


\begin{tabular}{|c|c|}
\hline REPORT DOCUMENTATION PAGE & $\begin{array}{l}\text { READ INSTRUCTIONS } \\
\text { BEFORE COMPLETTNG FORM }\end{array}$ \\
\hline \begin{tabular}{l|l} 
T. RLPOHT MUMCER & 2. GOVT ACCESSION MO \\
ARI Research Product 85-29 & $46-417099$
\end{tabular} & 3. RECIPIENT'S CATALOG NUMEER \\
\hline \multirow[t]{2}{*}{$\begin{array}{l}\text { 4. TITLE (and Smetto) } \\
\text { COMPARISON-BASED PREDICTION OF COST AND EFFECTIVE- } \\
\text { NESS OF TRAINING DEVICES: A GUIDEBOOK }\end{array}$} & $\begin{array}{l}\text { 5. TYPE OF REPORT PEAIOD COVEAEO } \\
\text { Final REPOIt } \\
\text { April 1983-June } 1985\end{array}$ \\
\hline & $\begin{array}{c}\text { 6. PERFORMING ORG. REPORT MUMEER } \\
\text {-- }\end{array}$ \\
\hline $\begin{array}{l}\text { 7. Autrond } \\
\text { Klein, G. A., \& Johns, P. (Klein Associates); \& } \\
\text { Perez, R., \& Mirabella, A. (ARI) }\end{array}$ & $\begin{array}{l}\text { CONTRACT OR GRANT MUMEER(O) } \\
\text { MDA } 903-83-C-0270\end{array}$ \\
\hline $\begin{array}{l}\text { DenForminO ORGAMIzATION MAME AMO ADORESS } \\
\text { Rlein Associates } \\
740 \text { Wright street } \\
\text { Yellow Springs, OH } 45387\end{array}$ & 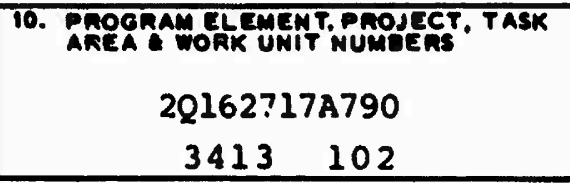 \\
\hline \multirow{2}{*}{$\begin{array}{l}\text { 11. CONTROLLIMO OFfiCe MAME AMD ADONESS } \\
\text { U.S. Army Research Institute for the Behavioral } \\
\text { and Social Sciences } \\
5001 \text { Eisenhower Avenue, Alexandria, VA 22333-5600 }\end{array}$} & $\begin{array}{l}\text { 12. REPONT DATE } \\
\text { July } 1985\end{array}$ \\
\hline & $\begin{array}{l}\text { 13. MUMDER OF PAOES } \\
\qquad 94\end{array}$ \\
\hline \multirow[t]{2}{*}{ 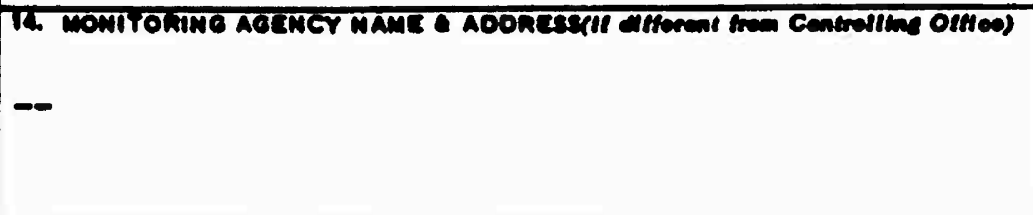 } & $\begin{array}{l}\text { 16. BCCUnITY Class. (ol the report) } \\
\text { Unclassified }\end{array}$ \\
\hline & $\begin{array}{l}\text { TBa. DCCLASTRFICATION/DOWHORADIMG } \\
\text { SCHEOULE }\end{array}$ \\
\hline
\end{tabular}

Approved for public release; distribution unlimited

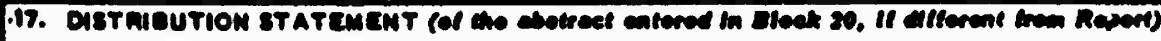

$-$

10. SUPPLEMTANY MOTCS

Contracting Officer's Representative, Ray Perez.

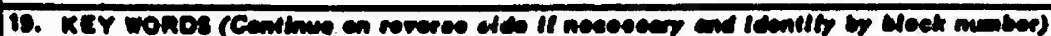

Maintenance training

Training devices

Training effectiveress assessment

Operator training

Transfer of training

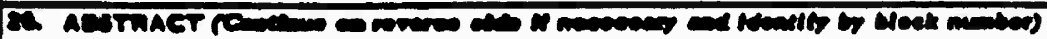

IThis Guidebook is part of a larger project to develop comparison-based prediction (CBP) techniques to estimate the effectiveness of new training devices and to renerate design recomendations. The document explains why and how the methodology can be useful and then gives step-by-step instructions on ho:! to apply it.<smiles>CCCC</smiles> 


\title{
Comparison-Based Prediction of Cost and Effectiveness of Training Devices: A Guidebook
}

\author{
Gary A. Kloin and Paula Johns \\ Klein Associates \\ Ray Porez and Angelo Mirabolla \\ Army Research Institute
}

Training and Simulation Technical Area
Stanley Bolin, Chief

Training Research Laboratory Harold F. O'Nell, Jr., Director

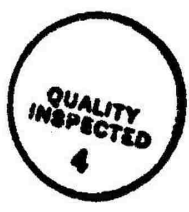

\begin{tabular}{|l|}
\hline Accesion For \\
\hline NTIS CRAQ1 \\
DTIC TAB \\
Unannounced \\
Justification
\end{tabular}

U.8. ARMY RESEARCH WSTITUTE FOR THE BEHAVIORAL AND SOCAL SCIENCES

5001 Eisenhower Avenus, Aloxendria, Virginia 22333-5600

Office, Deputy Chief of Staff for Personnel

Depariment of the Army

July 1985 
ARI Research Reporis and Technical Repuris are intended for sponsors of R\&D tasks and for other research and military agencies. Any findings ready for implementation at the time of publication are presented in the last part of the Brief. Upon completion of a major phase of the task, formal recom. mendations for official action normally are conveyed to appropriate military agencies by briefing or Disposition Form. 
An ARI mission is to produce technology (1.e., job aids) that will help Arwy training developers design, acquire, and use simulation-based and computer-based programs of instruction for weapon operation and maintenance. A critically needed aid is one that will help the Army design and evaluate training devices early in the reapon acquisition cycle.

One approach to such aiding--comparison-based prediction (CBP) is the subject of this report. The approach has been used successfully as part of the HAPDMAN wethod for estimating new bardware reliability. We are now trying to exploit CBP as a wethod for estimating the effectiveness of training devices as early as the drawing board or prototype stage of training development.

The current effort translates several years of scientific research and developmental testing into user-orlented guidelines. These guidelines can help PW-TRADE and training developers in TRADOC make better informed and docunented decisions.

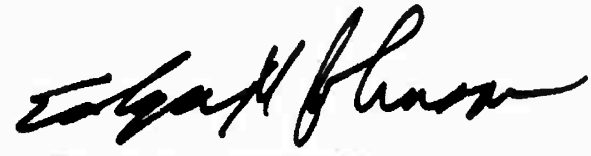

EDGAR M. JOHHSON

Technical Director 
COAPARISON-BASED PREDICTION OF COBT AND EPPBCTIVENESS OF TRAIMIKG DEVICES: A GUIDEBDOK

I. IMTRODUCIMG THIS GUIDEBOOK ................. 1-1

Oojective .......................... 1-1

Comparison-Based Prediction ............... 1-4

Phase I - set Up Your Problen . . . . . . . . . . . . 1-8

Phase II - Select Specif1c Resources ............. 1-8

Phase III - Collect Your Date . . . . . . . . . . . 1-8

Phase IV - Make the Prediction ................ 1-9

Background ........................ 1-10

II. HOW CBP WORKS: A QUICK EXANPLE . . . . . . . . . . . 2-1

Bett1ng Up the Problem ...................... 2-3

Velecting Specific Resources ................. 2-3

Collecting the Data ................... 2-4

Making the Prediction .................... 2-7

III. SETTING UP THE PROBLEN . . . . . . . . . . . . . . 3-1

Selecting the Prediction Target ............... 3-1

Listing the Causal Factors (High Drivers) ............ 3-5

Constructing the scenario ................ 3-12

IV. 8ELECTIM THE RESOURCES ................. 4-1

Choosing the Comparison case . . . . . . . . . . . . 4-1

Selecting the Expert .................... $4-3$

Alternative strategies ...................... 4-4

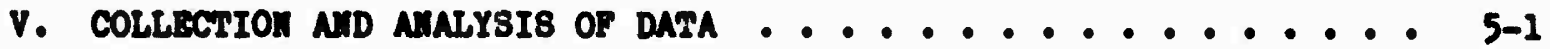

Preparing for the Interview ................... 5-1

Conducting the Interviev ................. 5-2

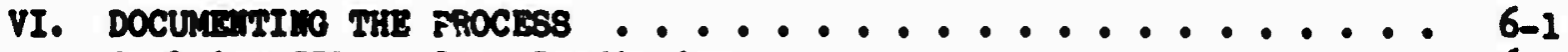
Applying CBP to Cost Predictions ................ 6-2

vII. MNACIMO THE CBP PROCBSS . . . . . . . . . . . . . . T-1 Log1et1cs .......................... T-1 Conclustons ..................... T-3

RAmRECE ............................... 8-1

APPEIDIX A. COMPARISON-BASED PREDICTION . . . . . . . . . . A-1

B. SANPLE PORHS ..................... B-1

C. ThRE CASE Studies .................... c-1 
Page

\section{LIST OF TABLES}

Table I. Elewents of the CBP methodology .............. 1-7

If. Checklist for $T(A)$ selection ................ 3-2

III. Measures ..................... 3-2

IV. Illustration: Some causal factors affecting the measure

$(T)$ of training device effectiveness .......... 3-10

v. (Some) factors to consider in developing the scenario .... 3-13

vI. strategr options .................. 4-7

\section{LIST OF FICURES}

Figure 1. Potential for change vs. data avallability .......... 1-1

2. Comparison-based prediction process ........... 2-2

3. Causal factors ................. 3-6

4. Illustration: Sone causel factors affecting the weasure

$(x)$ of training derice effectiveness ........... 3-8

5. The CBP interview .................. 5-3 


\section{CBP GUIDE}

CHAPTER I: INTRODUCING THIS GUIDE

\section{OBJECTIVE}

The objective of this Guide is to explain to training device developers how to use the Comparison-Based Prediction (CBP) method to estimate the cost and effectiveness of new training devices. $B y$ training device we mean any equipment that represents or simulates the equipment and tasks of the systew whose use is being trained. This can include the system equipment itself as an Actual Equipment Trainer. This Guide describes a way to make better predictions early in the design sequence.

Why do we need such a methodolory? Consider Figuze 1. It represents the fundamental challenge of the equipment procurement cyele: that the potential to make insxpensive changes declines as the procurement cycle progresses, while the data for deciding on these changes are not available until the cycle is almost completed.

\section{Figure 1.}

Potential for Change vs. Data Avajlability

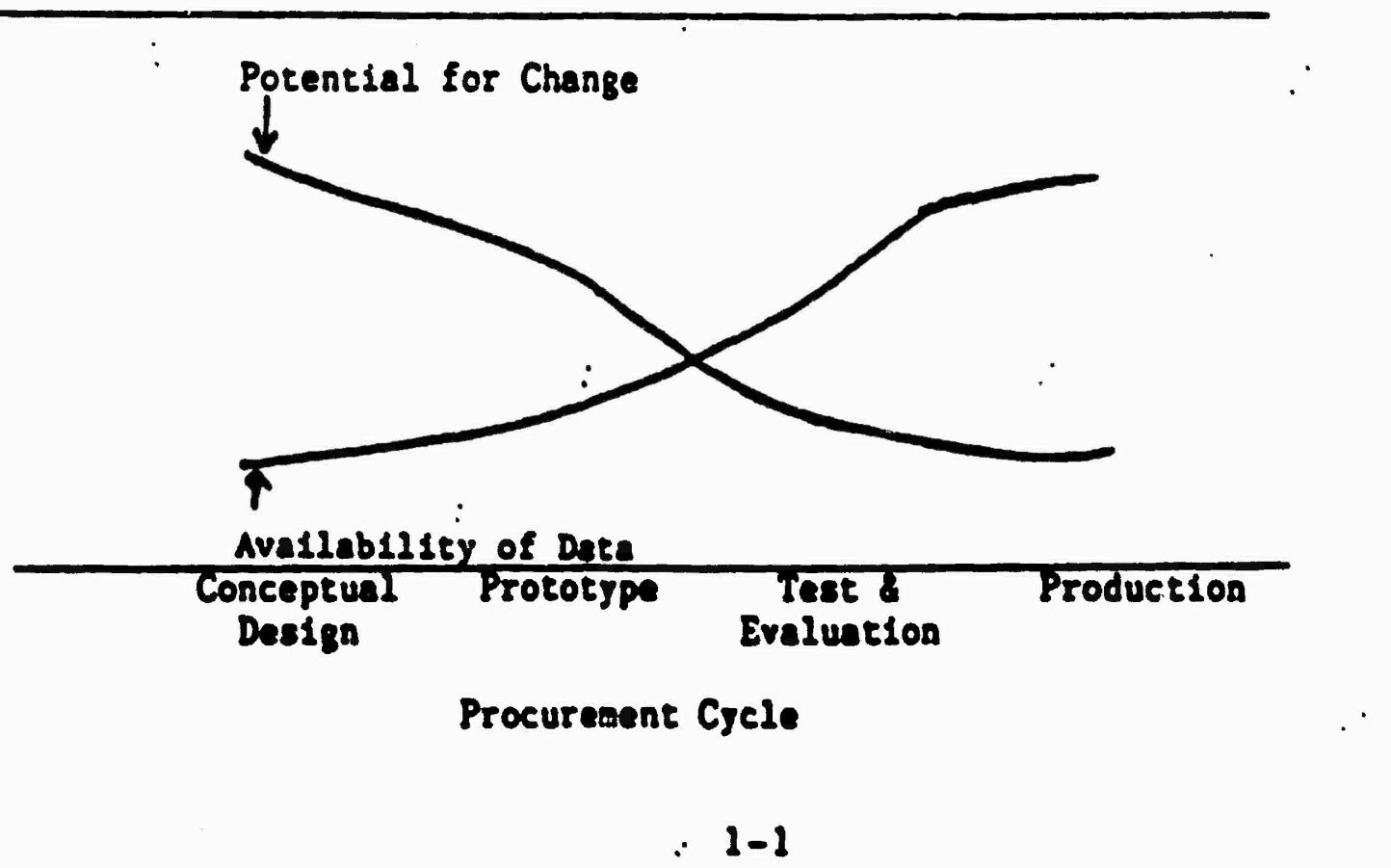


Most cost effective decisions about the need for and design of a training device must be made early on. Decisions involving fidelity and function, type of training - all have to be made almost before the system itself is developed, and well before the training device has been constructed and can yield operational data. Yet most prediction models require considerable data about the device, data which are not available until much later in the cycle. Therefore, a prediction method is needed that is not data driven, that can operate with information from sources other than the system under design.

Why is Comparison-Besed Prediction useful? Because it uses experience with devices siwllar to the one under design, and therefore can be used early in the cycle, at the Training Development Study (TDS) or Cost and Training Effectiveness Analysis (CTEA) stages. It does not require operational data from the new system.

There are other techniques in use, ranging from reliance on expert judgment, at the simplest level, to matheaatical models, at the most complex. But expert judgment by its nature is subjective, and it can be difficult to evaluate such predictions or justify then to others. And, at the other end, complex systens require large scale models to enconpass all necessary factors that affect training effectiveness, and there aay not be the operational data needed to feed such a model. While all the data and knowledge needed to feed prediction modelsiag eventuially becone available, it is useful to have a reliable way to make decisions early in the cycle.

Comparison-Based Prediction provides a technique that is between unstructured expert judgents and complex date-drivan oodels. It is a aethod for structuring expert opinion, so that 
it makes use of the data that is available about similer cases. It -

provides an audit trail of such judgments, so that thes can be evaluated, compared with other predictions, and adjusted as the design process advances.

Who is 11kely to use CBP? Many people are involved in the development of training devices at different stages of the procurement cycle. Potential users may be personnel in Army training operations, responsible for the design and development of training programs or courses for new or modified systems. They way be personnel in contractor organizations, who wust develop training requirements for new material. They could be personnel in program managenent offices (PMOs) responsible for training-program needs of new system development. Or they may be personnel in other wilizary organizations, such as TRADOC system manegers; or at other levels, such as TRASNA or PM TRADE, who have responsibility for training prograd developmeat.

They need to answer such questions es: What type of training devices (for example, 3-D or 2-D?) should we coasider for this system? How much should be budgeted for developing, operating, and maintaining a training device for this system? What will be tha nost cost effective training device for this systen? What will be the characteristics of an effective device? Which training device will be nost effective under these particular circuastances? 
What is this methodology? Comparison-besed Prediction (CBP) is a method of reasoning by analogy, where an inference is wade for one object or event based upon a similar object or event. It is the use of concrete experience as a basis for predicting the future, making adjustments on the basis of key differences between the cases. Later In this manual, we will go into the nethod in considerable detall. And in Appendix A, we discuss the development of CBP and the research done with it to date. For now, let us describe this tjpe of reasoning by a sipplified, every-day exaeple that w1ll 1llustrate its priaciples and elemencs.

Whan hoacowners decide to sell thelr house, they are golag to do something they have never doae before. They any have had experience in buying and selling other homes; however, selling their present hose represents a undque, if sintlar, eveat. They aed flrst to predict a realistic selling price - oae which aot oaly will ettract a buyer but also w1ll give then an optinue retura on their investenat. .

They w1ll turn to an expert, perhape an eppralear, or a radtor who is knowledgeable about narket prices for other houses bought and sold in their nelghborhood. The expart 111 conpare their house with others nearby that have cold receatly or that are on the arket, choosing ones that are like It In inportant features such se size, or age, or type of construction. The hoscowars an decide to get oplatone fron nore than one expert, or fron percons utth a vartaty of knowledge or experience. The general strategy is to cack expert opinion that is bead on knouledge of coeparable cases. The aose Leportent elenents ore Ideat1fyias kaouledgeable experts and Iladias appropriate caces to use for conparison. 
The way an expert, such as a realtor or appraiser, proceeds is to identify the important factors that influence the selling price. These generally include those on which the selection of comparison cases was wade, and other factors specific to the houses, such as number of bathrooms, or size of grounds, or orientation on the lot. Other factors in the situation are also noted, such as whether mortgege rates are rising, whether housing is scarce, whether the schools are good. The expert will firally winnow down a full list of important factors into those few, perhaps no wore than five; that currently have the most influence on price.

The next step will be to assess the differences, between the comparison houses and the one under evaluation, or these important factors. The expert will examine them one by one, first to assess the direction of the difference, then to refine a measure of its magnitude. For example: the home may have four bedrooms, while the comparison case had only three. The extra bedroom w111 probably mean a higher selling price, but just how wuch is yet to be determined. At the sawe time, perhaps the howe for sale has only one bathroom, whereas the comparison house had two. On this factor, the price may be expected to be lower than that for the comparison case. The expert later will fine tune the effect of these factors, with realistic adjustwents based on experience.

The outcome is a price that started as the selling price on a cosparable house or houses, adjusted up and down by an expert, on the besis of differences between this house and the other(s) on certain Important factors. In addition, there is a clear record of this process. The expert did not pull a figure out of the air, and the howeowner knows the basis for the decision. The price can be 
justified to those who must evaluate it; and if: there should be a change in one of these factors -- or if the experience with one of the comparison cases should turn out to be different - an adjustment.can easily be made.

This is an example of how reasoning by analogy works, and how we accept it as a useful methodology in areas that are important. Note that the expert could have developed a model, putting a price on each and every feature of the home and then adjusting for certain known factors. There are times when that is not practical or racessary; the use of analogy allows us to concentrate on only the most important variables.

While identifying many possible causal factors, the realtor settled on those few that currently were likely to have the most influence on price. Since a few factors gerierally account for the largest part of the differences between cases, the marginal value of additional factors is low. By using a well chosen analogy, we incorporate the vital elements of our subject, without having to know why they behave as they do, and focus on what is different about the new situation and what effect those differences will have. In effect, we have controlled for those many variables which are common to both cases.

Using the example of the home sale, let us define the elements of the CBP method. Then, we will build a model of the methodology. Table I l1sts the elements in the example of the home sale and shows the formal element of CBP methodology which each illustrates. 
Table I

Elements of the CBP Methodology

Element in

Illustration

The rome being sold

selling price

Selling price for A

The realtor, perhaps other

aporaisal experts

Other homes, previously sold

Sactors that may influence

the selling price of $A$

(e.g size, age, number of rooms)

Final list of most important factors, their specific values and how they affect one anothe?

Decision on how meny comparison houses (B) to use and how many and what kinds of appraisors to use

selling price for a comparison house

Documentation/Report on how selling price of the target house was estimated
CBP

Element

- - - -

Target Case: A

Target Variable: T

Target Value: $T(A)$

Subject Matter Expert (SNE)

Comparison case(s): B

Cáusal factors

(Erom which high

high drivers are

selected)

Scenario

Strategy

Comparison Value: $T(B)$

Audit trall 
The steps in using Comparison-Based Prediction al s summarized as follows:

PHASE I -- SET UP YOUR PROBLEY:

1. Specify the target, the device for which you are trying to predict cost or effectiveness. This is called A.

2. Define the measure of that cost or effectiveness. This is the target variable $T$; this is what you are trying to predict, what you need to know.

3. Identify the wajor causal factors (high drivers) that will affect the target variable for $A, T(A)$.

4. Deteraine a context, or scenario, for your prediction, bullding in values for the high drivers. Under what conditions will $A$ operate? How will the target value $T(A)$ be measured?

PHASE II -- SELECT SPECIFIC RESOURCES:

5. Identify comparison devices B (1...n); if you are not knowledgeable here, jou ar have to consult with othere who are.

6. Exanine the CBP strategies to select the one nost relevant to this problen.

7. Choose knowledgeable subject natter experts (SHEs), ones fanlliar with the conparison device if you have already chosen that. For sone problens, you may need no expert but yourself.

PHASE III - COLLECT YOUR DATA:

8. Deteraine, with your SHF, the comparzeon value $T(B)$. This w111 be the ane variable, $T$, that you chose for the target device; but for the conparison case, the value, $T(B)$, should be known already. In sone cases, there will be no date avallable for $T(B)$, and your SME will have to estinate thes.

9. Presant the high driver 11st. Exagine the ecenario differeaces between cases $A$ and $B$. Betinate the offect of these differences, one by one, on the conparison value $T(B)$.

10. Adjust the value of $T(B)$ to $\$ 110$ w for the differeaces between $B$ and $A$. 
PHASE IY -- MSKE THE PREDICTION:

11. Determine a value for $T(A)$ from this adjustment.

12. Document this prccess to leave an eudit trail." This becomes the basis for evaluating this decision, or revising it as development proceeds.

Why would you want to use this method? We have already discussed the need for predicting training device cost and effectiveness early in the design cycle. Here are some reasons for using this approach in particular:

\section{ADVANTAGES OF CBP}

CBP has characteristics that make it especially useful early

in the training device development cycle.

DATA. - It does not require a great deal of data about the targetfor which predictions are needed.

EXPERIEICE -- The predictions are derived from operational experience, not theoretical models.

STRICTLRE -- It uses expert judgwents, but it structures those judgrents to increase the quality of the predictions.

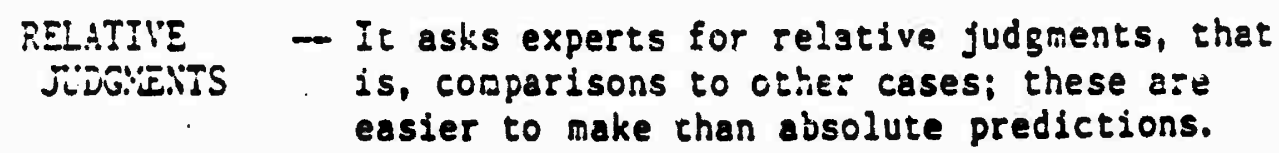

DOCLIENTATION - It creates an audit trail of the prediction process; the decision can be explaineo and justifled and, as development proceeds, the prediction can be updated. 
When is the use of the CBP method inaperopriate? As any

method does, CBP also has its drawbacks. These can show you when not to apply CBP.

$$
\begin{aligned}
& \text { DRAWBACKS OF CBP } \\
& \text { DATA - } \\
& \text { CBP requires data from specific cases, not } \\
& \text { summary statistics, and such case data may } \\
& \text { not exist. They may be estimated; and } \\
& \text { though subjective, they are systematically } \\
& \text { collected from experts who base them in } \\
& \text { their own experience, thus reducing error. } \\
& \text { If data for a formal model are available, } \\
& \text { then a reliable model should be used.. } \\
& \text { SUBJECTS - } \\
& \text { use's simplistic model may invite too casual } \\
& \text { disagree on who is expert. Using CBP } \\
& \text { successfully requires credible experts. } \\
& \text { CASES - C 's that are comparable to the one under } \\
& \text { cousideration must be known for the method } \\
& \text { to be successful. However, it" s rare that } \\
& \text { e device should be so unique as to have no } \\
& \text { similarities to others. }
\end{aligned}
$$

\section{BICÄUROLID}

Tire Army has developmentally tested the use of CBP for predicting the effectiveness of training devices. Applications involved autorotive maintenance trainers (AMIESS), videodisc gunnery simulators for tarits (VIGS), and trainers for self-propelled howitzer operations and maintenance (HIP). CBP methods have been used to predict such weesures as time saved in training and effectiveness of training. A study at George Mason University, not yet reported, predicting the effectiveness of training devices with varying degrees of physical and functional fidelity, yielded correlations of .90 between CBP predictions and test results (Klein, in process). In another study, training personnel indicated aore confidence in the predictions they made using CBP than in their own unstructured "expert" judgwents. 
Reesoning by analogy is already part of accepted military planning methodology. The Air Force has developed one procedure for such reasoning, Comparability Analysis $(C A)$, to preuict the reliability of new aircraft systems (Tetmeyer, 1976). Correlations between predicted and observed reliability of systems on A-10 aircraft ranged from .36 to .84 , the higher for cases where empirical data were available and did not have to be estimated (ilein \& Gordon, 1984).

To illustrate CBP in the Air Force, an engineer wishing to predict the reliability of the duct syster of a new aircraft finds a duct system on a comparable aircraft that is already in use. The operational data on the reliability of the existing duct system serve as a data base. The engineer identifies differences between the new aircraft and the operational one that affect reliability. If, for example, the duct system of the new aircraft is twice the size of the duct system of the existing aircraft, and there are no other important differences, then the engineer way calculate that the data for the new system will be twice the magnitude of the existing data. This degree of adjustment of existing data is termed the adjustment factor, in titis case $2 X$, or trice. The engineer applies this adjustnent factor (that is, 2X) to the operational data to generate a prediction for the new duct systew. Thus the prediction is based on the operational data but enhanced by the engineer's judgment of how to adjust those data to fit the new situation (in this case, to wultiple them by 2).

For a more comprehensive discussior. of the development of CBP. please see Appendix $\dot{A}$. 
This has been the who, what, why, and when of CBP methodology for predicting training device effectiveness and cost. We bave described a process that structures expert judgment, using data from comparison cases from the expert's own experience, and providing an audit trail for evaluation and update. The method is suitable for use earls in the design stage, when there is insufficient data for the use of formal prediction models. We are now ready to turn to the how of this process, and detail the steps in the CBP procedures. 
CHAPTER II: HOW CBP WOR̈KS: A Quick Exañle

Back on page 1-8 we sumarized the steps of CBP. We have turned that sumary into a flow chart, on page 2-2. Both of these sumparies can be referenced as you follow the hypothetical example below of a CBP application. In addition, hppendix B contains sample forms that support this example.

A vord about the diagram on page $2-2$. The flow chart is circular, suggesting the iterative nature of the process. Sometimes information received in one step will prompt you to return to an earlier step to rethink or adjust a decision made there. For example, you may choose a comparison case and, in a subsequent step, the expert you choose suggests a better case that you did not know about. These steps are not to be taken as rigidly sequential. Also, the same resources aay be used at different stages of the process.

This circular flow chart of the process is also a visual aid to the organization of the remainder of the Guide. You will see it printed at the top of each section, with the shaded portion of the diagram being the steps under discussion in the following text. It will be eailer to find your way in the process by making reference to the diagram on the page you are studying.

Throughout the example application in this chapter are insisted lists identifying the example's elements in terms of the elewents of CBP methodology. To assist your understanding, we also repeat the identification of eleweats from the hose sale example. And for each element, we also show its alphs symbol. 


\section{Figure 2}

Comparison-Based Prediction Process

PHASE I:

PHASE IV:

YHEE

PREDICTION

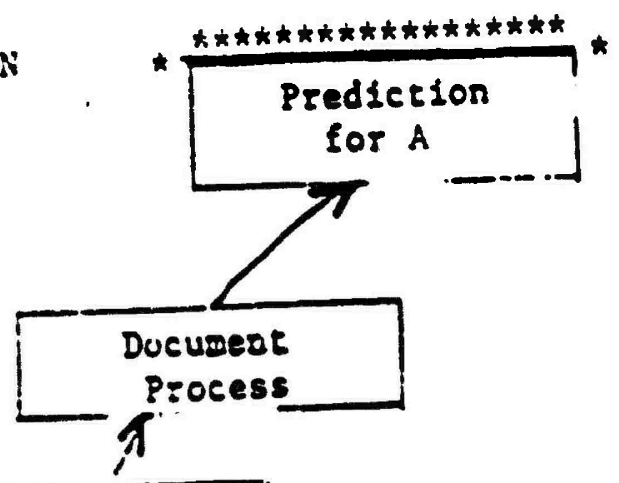

Deterrine

$I(A)$

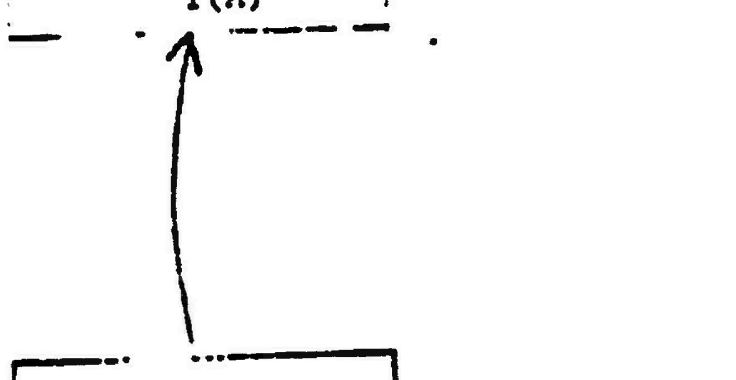

Acjuse

I(:)

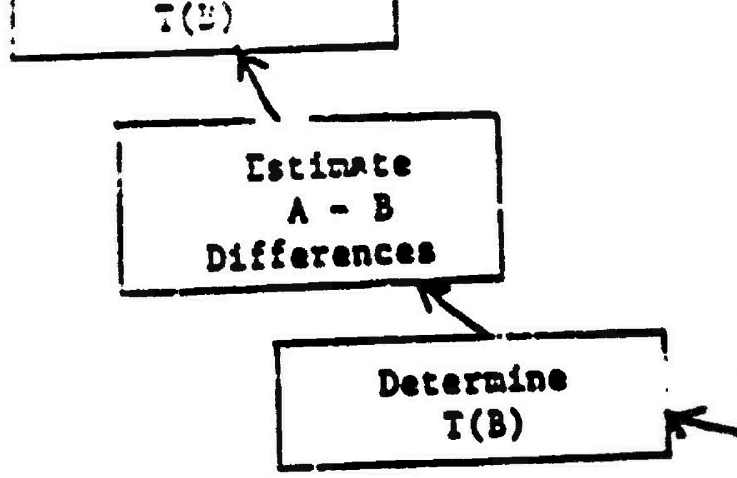

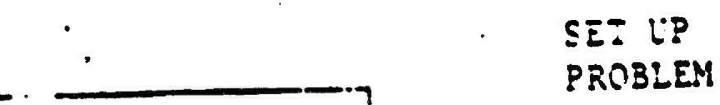

PROBLEN

PHASE III:

PHASE II:

\section{SELECT}

RESOURCES 
SETTING UP THE PROBLEM

The Army is building a new howitzer, and rou are charged with recommending a training device to be ready for use wher the howitzer is delivered. There are many decisions to be made: whether to use an existing device or build a new one; whether to use a simulator or recommend training on the actual equipment; and many others that would come before and after this level of recomendation. Assume that for our exanple you have narrowed in on trying to predict the effectiveness of a 3-dimensional, highly realistic training device that will have many instructional features, such as feedback mechanisms and recording devices. You have decided that the weasure of training effectiveness will be the number of direct hits the class neabers everage on their final test round.

\begin{tabular}{|c|c|c|c|}
\hline CBP ELENEIT & SYMBOL & : IN IHIS EXAMPLE & IN HOME EXANLL \\
\hline Target Case & $A$ & $\begin{array}{l}\text { Training device for } \\
\text { the new howitzer }\end{array}$ & Howe being sold \\
\hline Causel Factors & $C F$ & $\begin{array}{l}\text { Physical Fidelityi } \\
\text { Feedback Potential }\end{array}$ & Size, age, etc. \\
\hline Target lalue & $T(A)$ & $\begin{array}{l}\text { Average hits, finsl } \\
\text { test round }\end{array}$ & $\begin{array}{l}\text { Selling price } \\
\text { for } A\end{array}$ \\
\hline
\end{tabular}

\section{SELECTINC SPECIFIC RESOLRCES}

You Investigate and find that there is currently no device with this degree of Eidelity for training on the howitzer. You are not sure whether to choose as a cooperison case a howltzer training device that lacks physical fidelity, or a training device for a tank gun that 18 close to your subject in that it has the iaportant features of physical fidelity and feedbeck capability. You choose the tank gun training device but decide to use also a howltzer panel trainer that 
.. has good feedback characteristics.

\begin{tabular}{|c|c|c|c|}
\hline CBP ELENENT & SIMBOL & IN THIS EXANPLE & IN HOME EXANPLE \\
\hline $\begin{array}{l}\text { Comparison } \\
\text { Case(s) }\end{array}$ & B & $\begin{array}{l}\text { B1 Tank gun } \\
\text { simulator }\end{array}$ & $\begin{array}{l}\text { Other homes, sold } \\
\text { or on the market }\end{array}$ \\
\hline
\end{tabular}

B2 Howitzer panel

trainer

You decide to call on training supervisors as your SMEs, and choose tho for their respective experience in using the $\mathrm{Bl}$ and B2 training devices.

\begin{tabular}{|c|c|c|c|c|}
\hline CEP ELEIEIII & SYMBOL & & THIS EXMNPLE & IN HOYE EXAMPLE \\
\hline $\begin{array}{l}\text { Subject } \\
\text { Matter Experts }\end{array}$ & SMES & $\$ 1$ & $\begin{array}{l}\text { Tank gunnery } \\
\text { training supervisor }\end{array}$ & $\begin{array}{l}\text { Realtor, } \\
\text { eppraiser }\end{array}$ \\
\hline
\end{tabular}

You interview each S.EE separately, and have the SME consider only the training device which is the nost familiar. [NOTE: this is a choice of strategy.]

COLIECIIITU TIE DATA

Eefore starting the interview you draft a guide for it, so that jou will present each SVE with the same description of your proposed: training device and give the sawe definition of the causal factors (e.8. physical fidelity. Instructional features) you have identified. You also want to list the questions you will ask to be sure you cover the same ground with each one. You can plan on an interview of 45-60 minutes.

You find that in the training courses for howteers and for tank gunners, there are different designations for what jou thought of as an appropriate sasure: nubber of hits on final test round. Each S.E 
led you through the intricacies of. training and testing, and you wound up with considerable refinement in your description of the comparison target variable and the circli:stances under which it was reasured.

\begin{tabular}{|c|c|c|c|}
\hline CBP ELE'ENT & SYYBOL & IN THIS EXANPLE & IN HOME EXAMPLE \\
\hline $\begin{array}{l}\text { Comparison } \\
\text { Value }\end{array}$ & $T(B)$ & $\begin{array}{l}\text { You have specified for } \\
\text { each of BI \& B2 } \\
\text { the level of class, } \\
\text { specific round, ind } \\
\text { other details that } \\
\text { would equate I(B) as } \\
\text { nearly as possible to } \\
\text { T(A) as a measure of } \\
\text { each training device's } \\
\text { training effectiveness }\end{array}$ & $\begin{array}{l}\text { Selling prices } \\
\text { for the } \\
\text { copparison } \\
\text { cases }\end{array}$ \\
\hline
\end{tabular}

You and the SME review possible sources for finding operational data for the performance of the level of class you have chosen. The Aras, you discover, does not collect or keep shese scores in any systematic way. SMẸ 1 , the:tank gunnery training supervisor, happens to keep these data informally, as ay of checking out his instructors, so you can calculate a value for $T(B 1)$. SHE $\$ 2$ does not keep these date for his howitzer training courses; however, he feels pretty consident ebout estirating them for you, beceuse he goes over the scores before winding up each course and has a good feel for them.

\begin{tabular}{|c|c|c|c|}
\hline CBP ELEYENT & SMBOL & IN THIS EXAMPLE & IN HONE EXNPLE \\
\hline $\begin{array}{l}\text { Comparison } \\
\text { Target } \\
\text { Values }\end{array}$ & $\begin{array}{l}T(B 1) \\
T(B 2)\end{array}$ & $\begin{array}{l}14 / 20=70 \% \text { final } \\
\text { test round hits } \\
\text { estimated } 75 \% \text { final } \\
\text { test round hits }\end{array}$ & $\begin{array}{l}\text { Selling prices } \\
\text { for comparison } \\
\text { cases }\end{array}$ \\
\hline
\end{tabular}

You then lead each SME through an examination of the differences between his treining device and the one you are considering. You describe yours, and stress the high drivers you have Identified: physical fidelity, feedback provistons, performance data rerarding. 
SYE II feels that, based on those factors, your training device should train about as well as his does, and he would predict the same 70\% periormance for your classes. But he thinks of something else: the cosputer that his feedback and recording features operate from has always been poor, and is down so often that he feels it has impeded training. You both agree that by the time your training device is operationad, computer support should be such wore dependable. he tijigks this would produce better trairing and raise the average class score by a good $5 \%$.

SME 52 , in his interview, also examines the two training devices and the causal factors, Including the new one that SYE I Identifled. H1s training device is newer than SME I's, and he it satisfled with computer dependability. He doesn't think that ful: ;hystcal fldelity is $80 i .78$ so add wuch to training effectiveness, becsuse he sags his classes get in some practice on actual equipment before they take thetf stal test rounds. But he thinks the performance recording syste: shet you are building in will be not only a vase of time but aif actual deterrent to training. He thinks you are going to waste $: i=e$, sed your anstructors down with unnecezsary tasks, and in general distract frow what he considers to be the heart of effective training: drill and practice. He therefore thinks that, all things considered, your device ulll be slighely less effective than his is. narbe $5 \%$ so. 
MAKING THE PREDICTION

You now can make a frediction of your target value: the number of hits you expect the class, using your planned new training device, to average on their final test round. The first SME thought it would be another $5 \%$ higher than his own classes' $70 \%$ average: that is, he thinks instead of $14 / 20$ hits, they would have $14.7 / 20$ hits, or:

$\begin{array}{llll}\text { CBP ELEMENT } & \text { SYMBOL } & \text { IN THIS EXAMPLE } & \text { IN HOME EXAYPLE } \\ \text { Target value } & \begin{array}{c}\text { T(A) } \\ \text { estim'd } 73.5 \% \text { final } \\ \text { test round hits }\end{array} & \begin{array}{c}\text { selling price for } \\ \text { home being sold }\end{array}\end{array}$

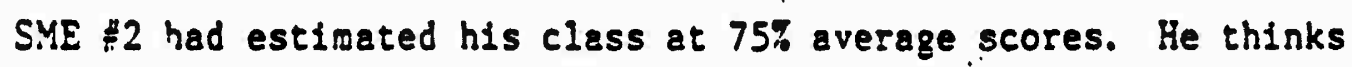
yours will be $5 \%$ lower, or:

\begin{tabular}{|c|c|c|c|}
\hline CSP ELEMEIT & SIMBOL & IN IHIS EXAYPLE & IN HOME EXAYELE \\
\hline , & $T(A)$ & $\begin{array}{l}\text { estim'd } 71.2 \% \text { final } \\
\text { test round hits ... }\end{array}$ & $\begin{array}{l}\text { selling price fo: } \\
\text { home being sold }\end{array}$ \\
\hline
\end{tabular}

You now have two expert opinions of what the training effectiveness, expressed in a class performance score, of your proposed device will be. The two scores are close, and jou could simply average them and use $72.4 \%$ for - working figure.

However, you have documented these interviews. (Remember the guide you drafted before the Interviews? You noted the answers on 1t.) Therefore, you are able to refer to your notes and try to resolve any discrepancies in judgments. And if your review supports feelings you may have had that you were not getting really responsive answers, you are free to reject an interview altogether.

In this example you tend to think, looking over their responses, that you trust SME 11 a little nore, because he keeps records. So jou think, If anything, gour estimate ay be a little low because of that. Whenever 
you use the $72.4 \%$, you will keep that in mind.

Your working figure for this prediction is about $73 \%$, with an expected range from $71 \%$ to $75 \%$. The two different estimates become like confidence limits for the prediction.

$\begin{array}{llll}\text { CBP ELEMENT } & \text { SYMBOL } & \text { IN THIS EXAMPLE } & \text { IN HOME EXAMPLE } \\ \text { Target value } & T(A) & 73 \%+/-2 \% & \begin{array}{l}\text { selling price for } \\ \text { home to be sold }\end{array}\end{array}$


CRAPTER THREE: SETTING UP THE PROBLEM

SEIECTING THE PREDICTION IARGET

It is not always easy to decide just what you wish to predict. When you are attempting a cost piediction, it is usuallg not difficult to specify your variable. But if you want to know the effectiveness of a prototype maintenance training device, you must decide just what weasure to use and what specific date you need.

The prediction variable, $T$, must be desined in terms of a clear question. If jou want to predict training effectiveness, jou wight begin by asking yourself, "If the training device does a good job, what measure will show a big before/after training difference?" For example, if you mean effectiveness for training in classroom, the $T(A)$ might be the number of hours needed to cover certain tasks. Or, it might be the accuracy or speed of student performance on a particular task, or some other measure. The important point is that you want to be specific about what jou mean by training effectiveness for a given case, and jou wust specify the measure of $1 t$.

You wust also think about who will be using your prediction, and how it will be applied. This will give you ideas about how precise your measure must be, and what form it might need to take. Do you want to compare this device with others? Or do you want to use this device in the solution of a particular training problem? Table II is a checklist of items to consider in selecting T. You may add to it as jou proceed with gour specific problem. Table III lists some general measures for relative comparisons. 


\section{TABLE II}

Checklist for T(A) Selection

What do you need to predict?

Are there standard measures?

Does $T(A)$ need more than one measure?

Who will use this result, and how?

Does your measure refiect training

device use?

How will you obtain $I(B)$ data?

\section{TABLE III}

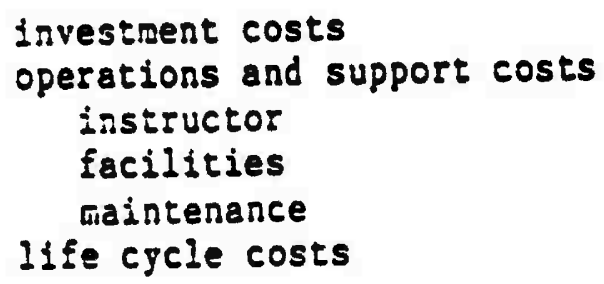

\section{MEASURES OF COST}

MEASURES OE TRAIIING

\section{EFFECTIVENESS}

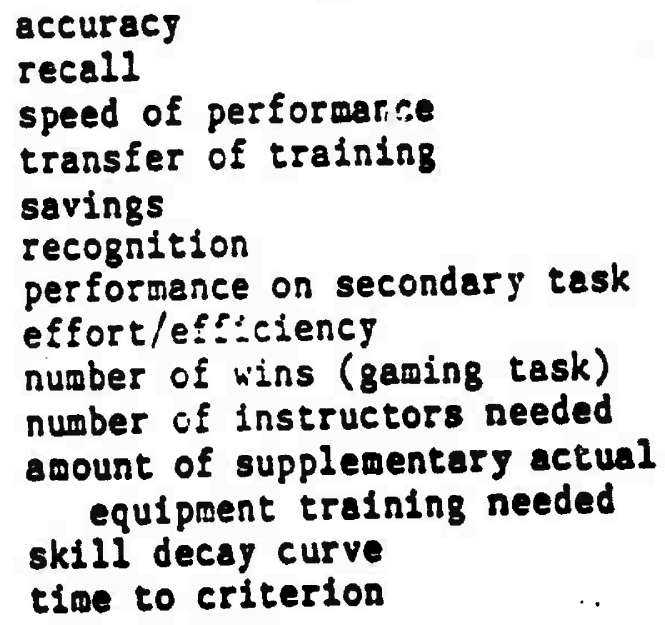


One factor that can guide the selection of $\mathrm{T}$ is the availability of comparable data for $T(B)$. That is, when you choose the target measure for predicting about A, jou are going to have to find the value of that same measure for your comparison case B. Your knowledge of available data for $B$ may influence your choice of measure. In predicting costs, for example, you know that there are cost data on record for comparison devices. When you want to predict training effectiveness, you may well have a problem finding comparable

The DoD does not maintain easily accessible records of the training effectiveness of existing devices, although sources are available. It is worth thinking about data availability before you decide on $T$. Sometimes you can find empirical studies of the effectiveness of comparison devices, and you can use the data as $T(B)$. Yore often there will be no such studies. At this point you way bring in a subject matter expert for help (not necessarily the same one who will work on the actual prediction).

The list of possible comparison cases (Bs) does not have to be shortened until iater in the CBP process; the final choice is not firrly aade until the interview, when that SME agrees to it. However, it is useful to take $T(B)$ into consideration early in your thinking. Knowing that you way have to estimate data for the comparison case will help you define your target variable: that is, it will encourage you to define a measure about which comparișon data can be estimated, and it will start you thinking early about how to get those estimates.

You will find at times that you have to develop a very detailed measure, and that this will require creeting a whole scenario of events within which to estimate comparison case data for it. Here is an example of where the choice of $T$ became very complicated: 
In predicting the effectiveness of a tank gunnery training device (the Videodisc Gunnery Simulator or VIGS), we had to construct a measure of skill sustainment, and came up with the following in consultation with our SMEs. Normally, there is no practice in the six wonths between the end of training and the start of field exercises. We wrote a scenario in which the men were to practice on the VIGS during these six wonths. We defined the taiget value $T(A)$ as the number of first-round hits a trainee who had practiced with VIGS might be expected to achieve at the start of field exercises. For a comparable $T(B)$, our SMEs had to estimate the number of first-round hits trainees would average if they had practiced with another training device.

There were no data, of course, for $T(B)$, nor even for first-round hits attainable after six months with no intervening training. So SiEs first had to estimate the number of first-round hits the men would have achieved at the end of training, and then estimate the decay of an intervening six-months without practice, in order to estimate the effect of practice with other training devices. 
LISTING THE CAUSAL FACTOR3 (HIGH DRIVERS)

All those characteristics of the device or its context that, differing in value from one scenario to another, can account for differences in the measure of $T$, are called causal factors. Those few factors, perhaps no more than five or seven, that account for the majority of the difference, can be termed hieh drivers.

io comparison case will be a perfect watch for the training device you are planning. The two training devices will certainly differ if you are planning one that incorporates new features, or leading edge technology. Therefore you must give some thought to the wost influential factors that could affect training. Central to the CBP methodology is the SMEs' ability to assess the impact of differences in these factors, especially to judge the impact on the variable of interest, T.

For example, if you are under pressing time limitations, the best first estimate of $T(A)$ may be simply the value of $T(B)$. Many ball park estimates of cost are made by copring cost figures from earlier programs. Such a figure is probabls a better prediction than one based on an open-ended unstructured estimate. But CEP improves the prediction by utilizing experience with training devices and structuring the experts' ability to judge the effects of differences between the new situation and the one they have experienced.

Figure 3 illustrates why we need attend only to the high drivers in our comparison of the differences between cases. For many, perhaps helf, of the characteristics we identify as causal factors, the impact of the scenarto will be the same on the comparison case factors as on the new devices. For example, the physical durability of a simulator 
Figure 3

CAUSAL FACTORS

Examine only the High Drivers in Comparison Based Prediction

Factors of same or similar value in $A$ and $B$ (controlled)
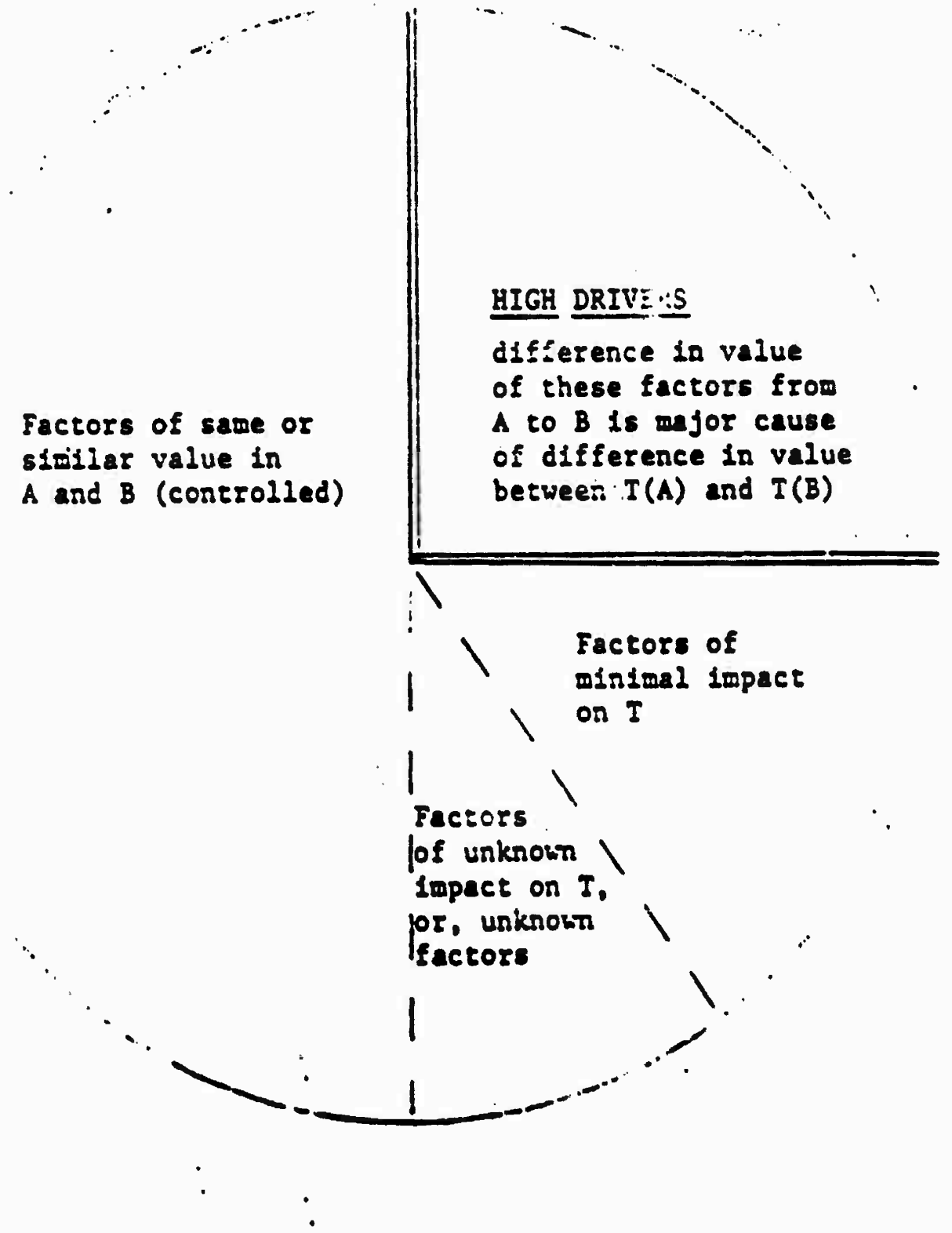
can be relevant to its effectiveness, but in the abserce of any information we assume that it will not differ from case to case and so do not create a scenario value for it. Physical duratility is a given and thus of no interest in our analysis.

For a smaller percent of the factors involved, the impact of differences in value is minimal and so not worth our effort to calculate. Another small portion of the factors are likely to be unknown to us and so cannot be examined in any way. These unidentified factors may be the source of error in our predictions.

Thus only a selection of the causal factors will qualify for our attention as high drivers: those which, differing in value from case $B$ to case $A$, will account for the major differences between $T(B)$ and $T(A)$, es Figure 3 illustrates.

The data we have found or estimated for $T(B)$ can be thought of as experience. The SME wili modify that experience to predict to a new case, $T(A)$. The identification of the causal factors is the first step in transforming our experience with $B$ into a prediction for $A$. The way thet modification of experience is done depends on the causal factors and how they differ in value in the scenario for $A$.

You may need to consult an SNE for this step, who may be someone other than the SME in your interview. Create a checklist of the most iaportant causal factors that w111 affect $T(A)$. Then examine these to see which ones were considerably different in case B. Rewember, elso, that we are looking at these factors in a specific context. While you w11l probebly begin with differences between the two trainiag devices, there may well be differences in the context - such as leval of student to be trained - that will have sizeable effect. Flgure 4 1llustrates this concept. 
Eigure 4

ILLUSTRATION: SOME CAUSAL FACTORS AFFECTING

THE MEASURE (T) OF TRAINING DEVICE EFFECTIVENESS

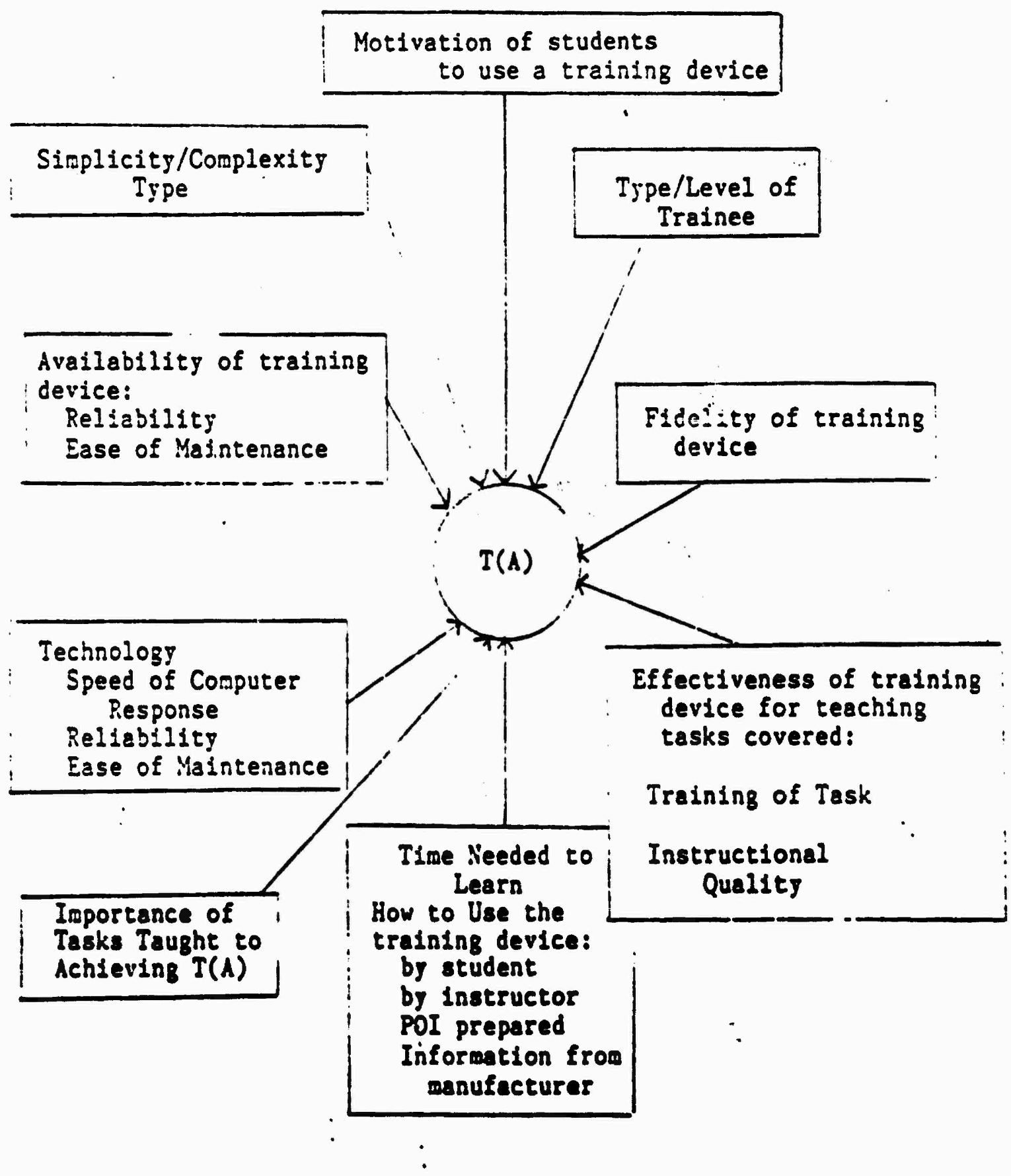


Some differences in equipment will have significant impact on your target variable. For example, the addition of a feedback mechanism, that allows the trainee to know performance accuracy and to identify errors, can be expected to affect the learning process significantly. Other features of the training environment, influenced by the training device design or simply part of its operations, might include: student motivation; the simplicity or complexity of the task; avallability of the training device; the level of student; instructional qualitj; or the realism of task presentation.

Table IV is a general checklist for your reference.

Try to limit the list of high drivers to five or seven, in order to simplify the job of the SME in the interview. But if in doubt, leave the inclusion of a factor to the SME's judgment. And try to define the high. drivers so everyone will know what they mean, so that the distinctions between them are clear.

An exapple of the listing of high drivers, and the nature of their possible effects, comes from a study predicting the effectiveness of automotive repair training devices. The proposed training device was to be for the irmg, but the comparison case wes an Air Force device. The high drivers that were identified included the following:

1 Computer Power speed should increase effectiveness by both increasing motivation and providiag incressed training time
12 Task Simplicity simplicity should Increase the chances of bullding an effective training device

\section{Trainee Level less experienced students are less confortable with simulators, are trainable on actual equipaeni}


ILLUSTRATION: SONE CAUSAL FACTORS AFFECTING THE MEASURE (T) OF TRAINING DEVICE EFFECTIVENESS

(Taken from a Tank Gunnery Training Device Application of CBP)

Causal Factors

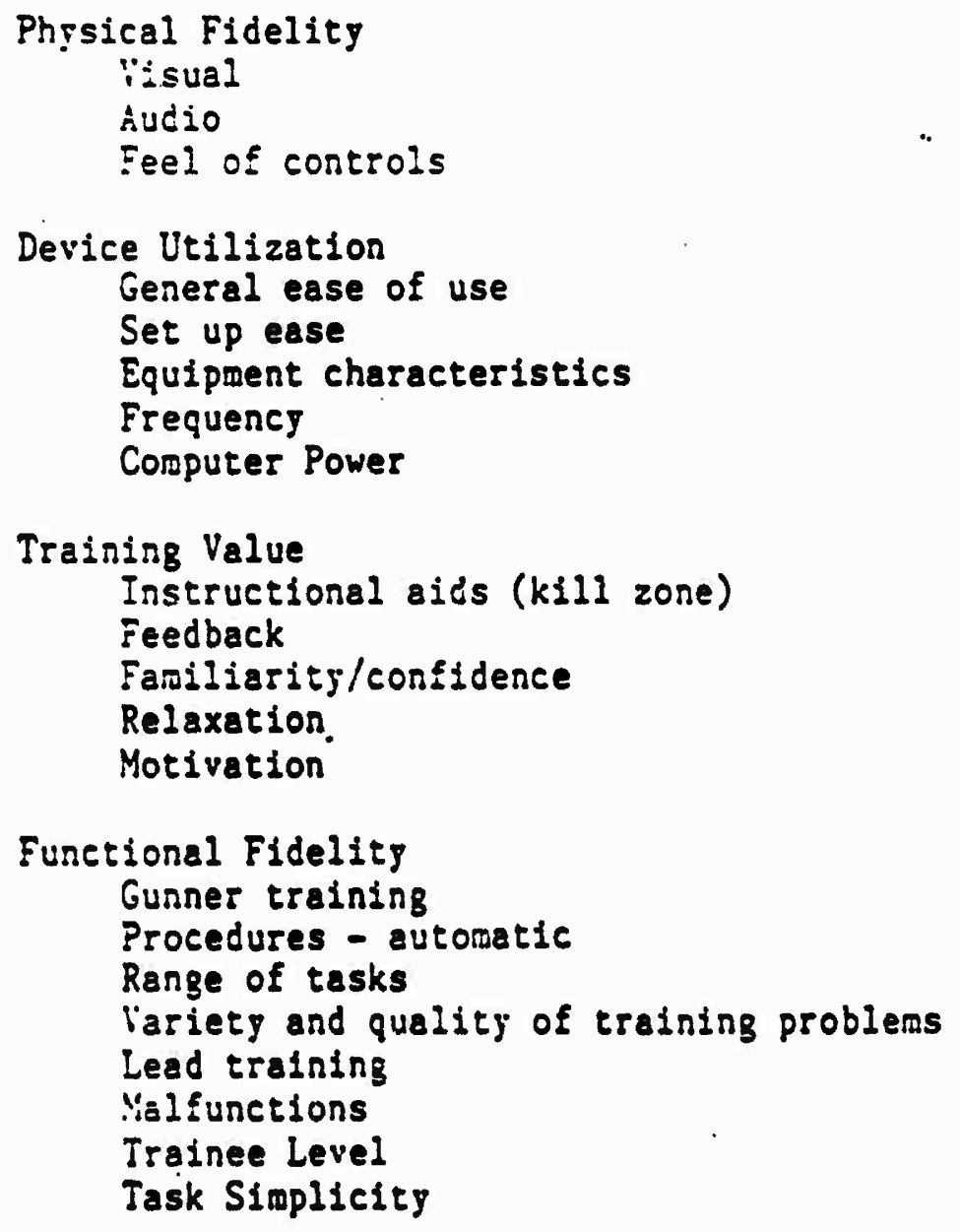

Task Characteristics

Task Simplicity

Crew Coordination

Trainee Level

Miscellaneous

Cost

Range 
These three factors were judged the rost powerful differences between the prediction case (Aray) and the comparison case (Air Force). They illustrate three kinds of high drivers (in accord with the taxonomy in Table IV: 1 is a training device equipment characteristic; 2 is a task characteristic; $\$ 3$ is a trainee characteristic.

To complete this example, although getting ahead of this chapter, we should tell you how the SME judged the effect of each of these causal factors. I was a reasure of training tire, expressed as class hours. Because the Army computer was to be faster, the same course could be taught in less time, thus reducing $T(B)$. Because the task that the Army would use the training device for was to be simpler, the time to teach would again be reduced. However, the Army was going to train students less experlenced than the Aif Force had, so the S.YE added some to $T(B)$.

This is shown in the following results:

\begin{tabular}{cc}
$T(B)$ & $T(A)$ \\
AIr Force & Army \\
\hline
\end{tabular}

1 Computer Power

$\$ 2$ Task Simplicity

3 Trainee Leved
-

$+(10 \%$ less time)

$+(16 \%$ less time)

$+(13.5 \%$ less

time)

Overall

$+(12.5 \%$ less tion than Air Force)

The outcone was a prediction of a $12.5 \%$ savings in tralning tiac for the projected Army training device, compared to tralaing ef me for the Air Force trainiag device. Since we knew the length of tine the Air Force training took, we could predict a tiac eavinge for the Aray. 
Prediction must be wade about events in sope context. A training device functions in a particular context with a defined range of task demands. In order to predict how well a training device will work, or what the value of a target variable will be, the person raking the prediction must know how the device will be used or under what conditions the measure will be taken. (MIL-T-29053B guides you is cestribiag instructionel sjster deviopment activities, including a Eunctional description of a training device.) It is a formal element of the CBP method called the scenario, or frame.

If you do not establish these details about the device $A$ - how it w111 be used, what tasks will be trained with 1t. atc., variarions can occur from one interview te another. Norse, the comparison case B way not be truly comparable with reapect to isportant details, such as type of trainees or conditions of training. You wouid then produce 'findings' that would be misleading or have no real value. For exasple, specify if lt will be used to trala new inductees, or to introduce officers to new specielty.

The seenario at elndeus should inciuts the high drtrers that sou have selected for this situation. It is in the seenario developaent that jou assiga velues to them. For exasple, every derice will have trainees; the level of trainee is specified in the sceanrio.

Table $V$ lists some of the factors to consider in developlas this scenario. Some of the factors that our experience has shown to be especielly relevant are a stateneat of the level of physteal fidelity of the training derice, of the conyenteace of uetas it in a class, and of how easily the training device alght be modified to acconsodate 
teaching different tasks as new ones are added to the course.

The scenario must provide a specification of the conditions under which the training device will be used, so that one or more experts (SMES) can judge its effectiveness in that context relative to other training devices. If the device may be used in different circumstances, which will have significantly different effect on its usefulness, the scenario may be appropriatels modified for a review of those differences.

\section{TABLE V}

(SOME) FACTORS TO CONSIDER IN DEVELOPING THE SCENARIO:

TRAINEES

Who are they?

-What is their experience level?

-Are they similar or dissimilar to current trainees?

TASR

What is to be trained?

Is the task specific? or generic?

- What are the criteria for learning?

PROGRAY What equiprent is involved?

Where is it administered?

Are there options in the unit?

- If in a school, what is the course?

- How will it be modified to include the training device?

DEIICE What physical features does the training device have? What instructional features?

What level of descriptive detail is needed? 
CHOOSING THE COMPARISON CASE

In this stage of the CBP process you will be making a tentative selection of one or more potential comparison cases (B) and choosing the Subject Matter Expert (SME) whow you will interview to obtain the needed information. These procedures are closely interrelated and must be pursued more or less together.

The first step is usually to prepare a list or menu of comparison cases. What this requires is that you identify other training devices, Including Actual Equipment used as Trainers (AET), and gather information about each one - where it 18 used, what tasks it trains, for what level of trainees it is designed.

It will likely be necessary to go outside your own experience to identify training devices that have siallarities of form or function to the device which you are considering. You should not 11mit yourself unnecessarily in this task, but should consider tasks or equipment that are similar to your own system, and consider devices that may be in use in other commands and even other services. Again, you may want to call on a consultant SME for this task. Remember, you need not be expert about the device you eventually w11l select. This is an opportunity to seek information about the full range of training devices that may be in use.

To select a good comparison case, use the list of high drivers to match it to your target case. The two should be as similar as possible on these important causal factors. Physical fidelity and task type are examples of high drivers that should be closely matched 
for: this is because their effects are so complex and important that the S.iEs could not realistically assess the effects of differences in them.

As you identify possible training devices, waintain a data sheet on which you enter the characteristics of each, so as to facilitate the comparisons and the choice of a final subject. (Samples of such a form are included in Appendices $B$ and $C$ ). Be sure to include those characteristics that you have already identified as likely causal factors. As you identify other elements of new training devices that you learn about, you way get further insight into what the high drivers should be.

While the job of identifying potential comparison training devices is yours, the final choice wust be made in conjunction with you: SME - who, by definition, is the expert on the topic. However, the final choice of SYE depends in part on your choice of comparison training devices, because you are seeking expertise on the training device, not expertise on a general subject. It is possible that, having identified likely training devices and chosen an SME who is knowledgeable, the SUE may then suggest yet another training device for use as a comparison case. It may be an entirely new training device, one that you had not discovered. Or it may be one you had. considered, which the SME knows well enough to value more highly than you did for use as a comparison case.

This is a situation where you want to use the expertise of the SME, once he or she understand's the problem. Guide the SME to select: 1) a case with which he or she is familiar; 2) one which will be a good match for the target case' with respect to the high drivers; 3) a case for which data are readily attainable. This task seens a 
circular exercise. Our circular system diagram, Figure 2, illustrates that it is!

SELECTING THE EXPERT

Since Comparison-Based Prediction relies on subjective judgments, jou need to find reliable and experienced personnel to make these judgments. All prediction methods rely on SYiEs at some point, either for the development of a model or for the estimates that go into it. This is a critical element of the process. It is essential to select individuals who will be able to make accurate predictions and also in whose judgments others will have confidence. Without credibility, predictive accuracy is useless.

To some degree, the choice of SME will also jepend on the way you have defined jour variable $T$. In the last analysis, the job for the SME is to adjust the data for $T(B)$ so as to produce a predicted value for $T(A)$. You way elect to use training personnel who conduct the courses in which the comparisca training device is used, and a training person way indeed be expert in its practical aspects. An SYE must, at a minioum, have the ability to conceptualize $T(B)$ as you have defined it. If you have devised some hypothetical measure of effectiveness for the SME to estimate, you rust have an SNE who will understand the objective jou are aiming for and be able to abstract his or her experfence for your needs.

If you have located research data on effectiveness, you may want to use research professionals as SMEs to adjust it. If you are working with operational data and estimates, you w111 want to use people with direct training experience, who will understand the context in which the data were derived and the variables that will be 
important as you pose changes to that context. Some sources for SMEs include ORSA, DOTD, school instructors, ARI research personnel, NIEC, etc.

If you have enough time and resources, you can use several SMEs: training researchers; systems designers; course instructors and supervisors. We will discuss this further when we consider different strategies for CBP. ALTERNATIVE STRATEGIES

There are a number of ways in which the CBP application can be structured. Your choice of strategy will deppend on such factors as time constraints, abundance of comparison cases, availability of data, and identification of SMEs.

Global Strategr. In the simplest application of the method, you will interview one SME, present all the relevant data about $A$, including the list of high drivers, and ask the SYE to make a judgment about $T(A)$ by adjusting what he or she knows about $T(B)$. You may try to elicit the answer in terms of an actual vaiue for $T(A)$, or you may receive only a statement about an adjustment to $T(B)$. But no further analysis would he undertaken. This is called the global strater.

As an example, you may be concerned to predict training hours needed for a specific task. The SifE know's that a comparabie training device uses 20 hours. Examining the high drivers and the description of $A$, the SME mey judge "25 hours for $A^{\prime \prime}$ or may 80 so far as to say only "maybe a fourth again the time for A." In this simple strategy, you would ask the SME only for his rationale; which one or two high drivers he considered. .

In enother example of the. global strategy, esticating the cost of a Howitzer Fire Control Panel Trainer, the SME selected a Multiple Launch Rocket System Trainer as the comparison case $B$ and used its cost as $T(B)$. She decided that for purposes of obtaining a ballpark figure, the effect of the high drivers could be discounted, and plugged $T(B)$ directig in as $T(A)$. 
Hich Driver Strategr. In a wore in-depth version of the CBP interview - the high driver strategr -- the SME is asked to detail how target case $A$ and comparison case $B$ differ from each other. The SME is given the checklist of high drivers and judges whether each of these differences favors the target case $A$ or the comparison case $B$, and whether any offset each other. The SME next estimates how much each of the high drivers affects the difference. The sum of these estimates is calculated during the interview. The SME then checks this calculation and is given opportunity to adjust it for reasons that must also be specified.

An example of this strategy would be found in Chapter 2's example of the howitzer prediction, if we had kept to only one S.ME. $T(B)$ was adjusted for three specific high drivers, one by one.

Multiple Comparison Stratery. Several comparison cases are used in the multiple comparison strategy. Basically you play a game of (fever than) twenty questions to pin down the velue of $T(A)$ by progressively narrowing the prediction range. If the value of $T(A)$ is smaller than $T(B)$ for example, the prediction may be further clarified and refined by comparison to other cases also judged to be smaller than $T(B)$. You need only two or three conparison cases before you have the prediction fairly well deterwined.

The use of multiple comparisons can serve to clarify and refine the judgment about the target measure. It can also serve to increase confidence about that judgment: if the same prediction is reached independently through the use of different comparison cases, we feel more certain about 1 ts accuracy. Also, if we use the judgoent of multiple SMEs and their judgments converge on the same prediction, our confidence is raised. 
As an example of the use of both multiple comparison cases and multiple SMEs, we have the AMTESS study appiging CBP to predicting effectiveness of automotive maintenance trainers in specific courses. There we used two sets of SMES: Army instructors who were trainers with the actual equiprent, and $A$ ir Force professionals famlliar with comparable training devices. One case yielded a prediction of a $17 \%$ savings in course time. The second yielded a prediction of $13 \%$ savings in course time. These predictions were accepted as in the same ballpark, and a composite prediction of $15 \%$ savings, $+/-2 \%$, was used to describe the results. The composite prediction was considered better than the single prediction because it included two different sources cf SME input yielding results which converged at a reasonably close value for $T(A)$.

This example; combining two strategies,. can be called a converzence strategy.

By having more than one comparison case you can usually build into your prediction wore causal factors for analysis - that is, new cases will probably have features that are differen: irom other cases, and so you may be able to find direct comparisons on more of the features of your-proposed TD. Remenber, jou are trying to locate experience comparable to your prediction case: the more experience with core variables that you can find, the tetter your basis for prediction.

When using multiple comparisons, try to keeg the interviews frow beconing too complex. SifEs should be asked to nake predictions based only on the training device with which they are most familiar. If they are really experienced with wore than one, then be sure you reduce the list of causal factors to a number that can be handled without confusion. Be very clear in the interview just which comparison case you are talking about at any time, and that you are comparing it to the proposed training device.

Table VI 11sts some strategy options. 
Table VI

Strategy Options

STRATEGY

Global

High Driver

Multiple

Comparison

Cases

Multiple SMEs
ADVANTAGES

Low resource demands
Explicit audit trail
Causal factors evident

Structured
predictions

Broader Input, cross-checks possible
DISADYANTAGES

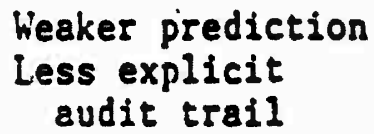

Difficult to use - with several SMEs and/or multiple comparisons.

Requires more time, and availability of multiple comparison cases

Requires more time and SIEs

Resultant prediction is complex

Cumuletive Strategp. You may also elect a cumulative strategy, adding SyEs until gou have enough agreement to feel confident. If jou collect data from wore than one SME, you can cross-check their results to see if there are disegreements. (NOTE that you should run onl! one SME at a time. When two or more are interviewed in the same session, the judgments of one are often dominant.) By examining the audit trail, you may find the basis for the disagreement in a misunderstanding, or in a difference of perspective, or in additional Inforwation that one had and the others did not.

If jou can Identify reason for the differences between SME judgments, you can feel wore confident in your ability to evaluate their combined judgment - that 1s, you can decide whether it is wiser 
to take it on the high side or low side, etc. And you have more confidence in the judgment because gou can evaluate the degree to which the experts agree with each other, knowing on what the differences in their calculations were based.

If, however, there is one SME whose judgment you value most highly, then you should use only this SME. Collecting more date will only add confusion. There is bound to be some difference between SyEs. Lnless you know you are goiag to edd velue by having more than one opinion, you should not seek additional ones.

If there is tide pressure for the prediction, and limited resources avallable for the CBP process, then select just the one best S.TE. 
CHAPTER V: COLLECTION AND ANALYSIS OF DATA

Now that you have selected your SME and decided on the strategy you will use to obtain the prediction you need, you are ready for the data collection interview. This should take place face-to face although it can, if necessary, be conducted over the telephone to save resources. Be extra careful about consistency here: jou lose the chance to catch facial expresalons that aaj show the SME's doubt or confusion about atep or question. PREPARING FOR THE INIERVIEN

As you follow the CBP aethod and conduct interviews with SHEs, you w111 need to refer to different kinds of inforaation. Prepare your aaterials well in advance and have then on hand when beginning the interview. These written naterials should Include:

- A description of $A$, the training device.

- A clear statement of the prediction target, $T(A)$.

- A scenario for $T(A)$. It will probably also include a brief description of the actunl equipeent syoten that the proposed training device is balng dealgned to train for, as wall as the device's configuration, hardware, and plan of instruction.

- A liet of potential conparison caces, Be. You need only brief Infornation on cach, olace the SHEs should select only conparison caces with which they are faniliar. When preparing a report, however, you any need to describe these coaparioun cases to others, so you should obtala sone description.

- The checkliot of high drivers. A brief explanation of each nay be needed.

- Basel1ne date for $T(B)$. If these w111 be est1ented by the SKE, there is nothing to pather in advance. If there are already cone data, alther operational data or research EIndinge, you an want to track these down before the Interview.

- A gloseary of CBP terme und definitions. 
It is important to prepare a data collection form prior to the interview. You way wat formal sheets for entering the date and judgments (see Appendix B for a sanple format), and an auxiliary notebook for recording coments. It is very easy to lose data if you are not prepared to record answers and changes in judgeents. You will also want access later to important comments that the SME may have added during the interview.

The date forn should include relevant background information on the SME. This will enable you to docunent his/her credentials as an "expert" in the area of interest. You also want to be able to locate the SME if follow-on questions are needed leter. If the SWE is ailitary, you should ack the length of his/her current tour of duty and where his/hor noxt posting is enticipated.

Before jou use the CBP nethod for the first tine, you should try a prectice epplication. This w111 let you test your plens for conducting the iaterview and collecting the date. It will holp you to think through all of the decieions concerning strategy that the Interview process requires.

CONDUCTING THE INTERVIEH

There is a clear cot of steps for the interview. leading to the objective of obtainiag a prediction (eee Figure 5). If thare is to be wore than one Interview, the guide is inportant also for the sake of consiatency fron one to another. As with nost face-to-face exchanges, however, It will be adified as it proceeds. The order in which the otope are taken way change, or cone an be ropacted as the SHE cones to underatand the procese. Therefore the firet requirenent is an Interview sulde, propared in advance, to aseure that you do not onlt 
any steps and that you can describe how you conduct the interview.

FIGURE 5

The CBP Interview

Step 1 Introduce task.

Step 2 Describe A.

Step 3 Determine $B$.

Step $4 \quad$ Identify high drivers.

Step 5 Establish $T(B)$.

Step 6 Judge global $T(B)-T(A)$ differences.

Step $I$ Specify $T(B)$ adjustment and predict $T(A)$.

Step 1 will be an introduction to the SME of the task and the CBP process. You may want to review briefly the guide to the interview that you have prepared. This is an opportunity to find out what jou need to about the SME's background and also to answer any questions he o: she may have. It should serve to put the SME at ease and to allow you some assessment of the level of understanding of the SME.

Step 2 has you describing the target training device $A$ and the systez for which it is to provide training. Explain the target Deasure $T(A)$ jou are trging to predict. Then describe the scenario or frape that you have developed for this measure. The SME way have, sowe suggestions here, or objections to what jou have devised. Be sure to note these comments. If you decide to sevise $T(A)$, be sure to specify on your data forn just what you have dose.

For Step 3 , discuss with the SME the choice of comparison case B. You way settle on one frow your list of possibilities or use a new one that the SME suggests. A short discussion should establish whether the choice is a suitable one, and the decision should be documented. 
Step 4 requires you to identify $T(B)$, the messure comparable to $T(A)$ for comparison case $B_{1}$ and, most important, to present operational data for it. If there are reported field data on the effectiveness of device $B$, these will, of course, be used. Next best would be research data on B. (Steps 3 and 4 include tasks you will. have addressed before the interview using other consultant experts.)

In Step 4 you will ask the SME to review your list of high drivers and amend it as necessary. The SME may add important causal factors of which you were unaware, or delete one or more which do not usefully pertain to $B$.

More often, though, no such data exist. In that case, Step $\underline{5}$ includes your asking the SME to estimate these data. Experience has shown that SMEs do not have difficulty in providing estimates. Give the SSEE the scenario you have developed for the westre of $T(A)$, and have $T(B)$ data estimeted for the same situation, as much as possible. Be sure to note whatever the SME wishes to say to describe how the estirate has made and what qualifications it was have.

You have now reached Step 6 , the criticsl phase of the interview -- asking the SME to predict the relative effectiveness of $A$ and $B$ in terms of T. The SME will estiwate whether T(A) is likely to be hicher or (1arger) for the target case $A$ than $T(B)$ is for the comparison case $B$ - or whether $T(A)$ is likely to be lower (or smaller) then $T(B)$. This relative judgment is based on what the SME knows about $B$ and what jou have told hid or her about $A$.

At this point, all you want to know is how the target deasure $T(A)$ and the comparison data $T(B)$ stand in relation to each other. Later you will ask for an assesisent of critical differences between 
the two cases to obtain a more nearls precise prediction. Siep 0 is an overall judgwent of the value of $T(A)$ relative to $T(B)$, that simply establishes two benchmarks for the final prediction: these benchmarks are the $T(B)$ and the direcsicn of change from 1t. This step is necessary because anslytical judgments of high drivers can interfere with global judgments, so the latter are made first.

For Step I, depending on the strategy you have chosen, the SME will refine and adjust $T(B)$. No two applications of CBP are the same and no model can outline exact procedures. Users will have to be flexible and creative in talloring each case to the particuiar need. With experience, you will learn to follow the line of reasoning jour SMEs devise, and to tailor your interview to the specific situations. The outcowe is $T(B)$ adjusted to produce $T(A)$.

We have written this section without examples, for the sake of focusing on the procedures. Appendix C detal1s three case studies, examples of the application of CBP to three problems, using different strategies, and detailing the interview procedures and the wethod of adjusting $T(B)$ to predict $T(A)$. They 11lustrate how eleaents within C5P change to flt specific needs and take advantage of avaliable resources. 
At this time, you have finished the main part of the task. You have completed the interview with the SME. You have generated a prediction for TiA). Now you must document the process.

The reason for documenting the prediction is so that others may understand how the prediction was generated. This can enable people to evaluate the prediction, or improve it, or update it as the design process roves on.

Your documentation should be concise. You need to describe the SME you interviewed (sometimes actual names would be used, but you need to be careful here if you have obtained information from an SME under an agreement of privacy). You want to name and perhaps briefly describe the comparison cases used, list the ways tiat the comparison case differed from the target case, and present the magnitude of these differences if jou have obtained such information. Last, you would present the prediction of $T(A)$.

It is very likelg that you have recorded additional data on your collection form, information that does not fit specifically into the prediction process. These may need analysis and presentation as weli. For example:

-- SMEs may have wade comments that will be of Incerest and concern, often about design features of the training devices under consideration.

- SMEs may have made comments that will be useful in planning new training programs for the systems in question.

For most applications, 1 to 2 pages will be sufficient. If the documentation runs to wore than two pages, begin with a brief summary or abstract outlining the salient points. 
You may want to present the prediction with a range for $T(A)$.

There are several ways to do this:

When an SME is estimating the magnitudes of the effects of the high drivers, you can ask for plus/minus values around each magnitude. At the end, you can add up the magnitudes to get the prediction, and you can add up the plus/minus valuss to get a prediction range.

For example, if there are three causal factors, the SME may say that the effect of the first is to add $\$ 10 R$ dollars plus or minus $\$ 2 \mathrm{R}$; the second may lower price by $\$ 50 \mathrm{R}$ plus or minus $\$ 5 \mathrm{~K}$; the third should lower it by $\$ 50 \mathrm{R}$ plus/minus $\$ 10 \%$. The result is a prediction of a cost $\$ 90 \mathrm{R}$ lower than the comparison:

\begin{tabular}{lc}
$+\$ 10 R$ & $+/-2$ \\
$-50 R$ & $+/-5$ \\
$-50 R$ & $+/-10$ \\
\hline$-\$ 90 R$ & $+1-17 K$
\end{tabular}

If you have more than one comparison case, jou can average them together, and use the range from the lowest to the highest estimate as the confidence range. If you use more than one SME, you can use the range of their predictions as the confidence range around a median. Other techniques may be used as well. None of these techniques meet the definition of statistical confidence limits, but they all reflect an ordinal scale of confidence. Users can rafer to these ranges where there are a number of predictions, to see which predictions to rely on and which to be skeptical about.

APPLIING CBP TO COST PREDICTIONS

Some form of Comparison-Based Prediction is already the basis for most cost estimates that you make. You see what the same or similar items or programs cost and adjust that figure based on factors such as quantity, inflation, or waterials.

If you have personnel inexperienced in cost estimates, then applying the CBP principles in this manual may be helpful in structuring that process for them. If you are practiced in estimating costs, this may provide you with some additionsl strategies. 
power of its elements, such as comperison cases and high drivers, and their identification and documentation. Strategies using multiple comparisons cases or multiple SMEs could add considerable strength to ang cost prediction.

For example, the HIP study applied CBP methods to the problem of predicting cost of a training device for an improved hovitzer still in the very early design stages. Three different comparison cases here located yielding different cost comparisons. The analysis of causal. factors, docupented in the study, pointed clearly to the cost implications of different design options. 
CHAPTER VII: MANAGING THE CBP PROEESS

As with any operation, the CBP process requires management

effort. Different steps in the CBP process require coordination, approvals, scheduling, the assembling of relevant data, and the preparation of written materials. These needs of course will vary with the specific task and the design of the particular study you are undertaking.

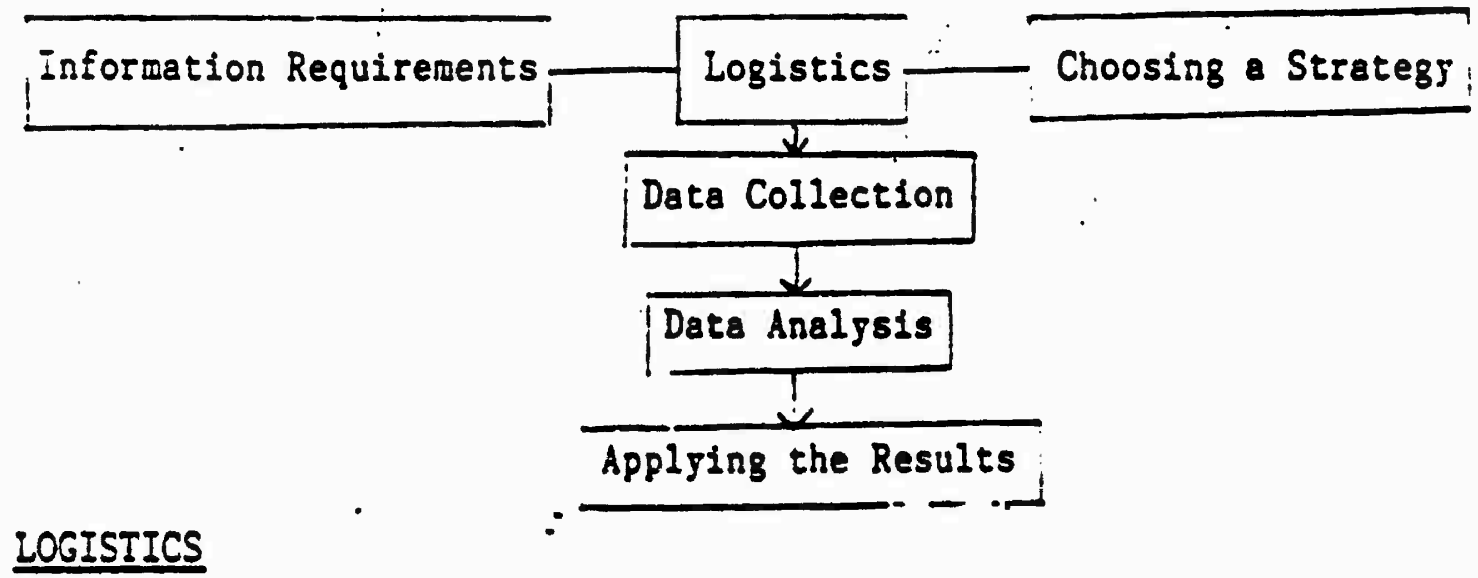

Here are some logistics issues you should be prepared to manage:

- Contects for the various information needs you have identified.

- Approvals for access to data, freeing time of SMEs, use of sacilities, and other needs.

-- hrraneements for meetings, interviews, su:veys, equipment inspections, and other interfaces.

- Scheduling of the process, time estimates, follow-up sessions, briefings, and other blocks of activity. It takes at least $30-40$ minutes to perform one CBP Interview - up to an hour. It takes 5-10 minutes to explain the task and the reason for collecting the information, another 5-10 minutes for background information, and another 20 minutes to obtain the prediction, including estimates for the impact of the high drivers. When collecting date for several target cases, and several target variables, a data collection interview can run up to two hours. A rule of thumb is to allow 20 minutes for each specific comparison needed. 
What is the Actual Equipment Trainer (AET)? Usually, a training device is proposed to replace training with a real piece of equifment. You will want to prepare a brief description of this AET to show to SNEs who might not be familiar with it.

What is the target device? You will want to prepare a description of what you currently know about the proposed training device. This includes its configuration, hardwre, ard plan of instruction.

What are the potential comparison cases? You co not need to gather wuch information on each, since the SME should select onis a comparison case that is familiar. However, in preparing a final report you may need to cescribe these comparison cases to others, so you should obtain some descizption.

What are the baseline data, the measure of $T(B)$ ? If these will be estimated by the SME, there is nothing to zatt.:? in advance. If there are already some data, either erational o: research findings, you should track these doir: before the interview.

Who are the SMEs? You may need to collect some general information on the SMEs avallable before selecting the one(s) you use. Furthermore, you may need to justify your choice(s) later, to explain why you included a specific SNIE in the study.

- What is on the checklist of high drivers? You will want to prepare a britf explanation of each high driver, so that you can sticw the SMEs how it differs from the others.

What is the target rariable? Will jou need any graphic aids to explain it to the SMEs?

Do jou have a frame/scenario, for $T(A)$ ? The SyEs w111 need to look at this to understand the pessure of training effectiveness $\mathrm{T}$. 
The emphasis of this Guide has been on explaining to you how to use the CBF method for mo: 1:ug predictions about the cost and effectiveness of new training devices. CBP helps make predictions early enough in the design and development aycle that planners can make the right decisions while it is early enough to carry them out. CBP is a cost-effective way to make early decisions about changes in trairing device design and use, and about production and distribution schedules.

If a new training program is needed for a new weapons system, CBP can 80 back to the closest comparison case (usually. the predecessor system) and assess the differences between the two so as to make design recommendations for the new program. This is an obvious use, and it is frobably alreads widespread as an infornal technique.

Another source of conparison is te identify training programs and training devices in other services and in industry that are comparable to the ones being considered, and to use the operational experience with these prograns and devices to make recommendations about what should be inciuded and excluded.

CBP formalizes these practices. It strengthens them by requiring the identification of high drivers and by documenting the process of adjusting data from the comparison case. It brings together the data and the SME for a sounder judgment.

In short, CBP can be used to take advantage of the operational experience that already exists. Rarely will a training device be entirely unique. If jou can find out the lessons learned elsewhere, and systewatically apply the to a new training systee, then you will be able to benefit ifrectly from past experiences. 


\section{REFERENCES}

Hoffman, R.R. (1980). Meteaphor in science. In R.F. Honeck and R.R. Hoffman (Eds.) Cognitive psychology and figurative Ianeugre. Hillsdale, $\mathrm{NJ}$ : Lawrence Erlbaum Associates. Klein, G.A. (1980). Automated aids for the proficient decision maker. 1980 International Conference on Cybernetics and Society, October. Mlein, G.A. (1SS1). a perceptual/recognitional model of decision makirij. Paper presented at Summer Computer Simulation Conference, hashingion. D.C., July.

Rlein, G.A. (1982). The use of comparsion cases. IEEE 1982 Proceedings of the Irternational Conference on Crbernetics and Society, 88-91. Klein, G.A. (1984). Comparison-based prediction of : ogram impact. Paper presented at summer meeting of Ohio Progran Eraluators' Group, Columbus, OH.

Ilein, G.A. (1984). Effects of time restriction on chess performance. Paper subgitted for publication, April.

Klein, G.A. (1985). Paper in progress.

Kiein, G.A., \& Gordon, S.E. (1984). Using comparison-based methods for F=eticison and desigring. Proceedines. Psichologr in the DOD Simposium.

Rlein, H.A., \& Klein, G.A. (1981). Perceptual/cognitive analysis of proficient cardio-pulmonary resuscitation (CPR) performance. Paper presented at the Midwestern Psychological Association Meetings, Detro1t, MI.

Rlein, G.A., \& Peio, R.J. (1982). The use of a prediction paradigm to studj proficient performance. Paper prepared for Honejwell, Inc. Rlein, G.A., \& Weltzenfeld, J. (1982). The use of analogues in 
comparability analysis. Applied Ergonomics, 13, 99-104.

Tetmeyer, D.C. (1976). Comparable item approach to establishing.

frequency of maintenance and maintenance tasks for a new aircraft.

Viright-Patterson AFB, OH Aeronautical systems Division, Crew Station,

Escape and Human Factors Branch.

heitzenfeld, J. (1984). Valid reasoning by analogy: technological

reasoning. Philosophy of Science, 5!, 137-149.

hidenhouse, C., \& Romans, W.W. (1977). A forecasting technique for

operational reliability (MTBF) and maintenance (MMH/FH). Technical

Report No. ASD-TR-77-28, Aeronautical-systens Division, Air Force

Systems Commend, Wright-Patterson AFB, OH.

8-2 


\section{COMPARISON-BASED PREDICTION}

Comparison-Based Prediction (CBP) is a wethodology for making predictions when there are unknown paraneters, missing data, or unclear objectives. Operationelly, it is a way of structuring the judgments that experts wake when they are called on to estimate unknown properties of a rew situation. Formally, it is a systed of reasoning by anelogy, predicting to en unknown ase by using what is known about a comparabie case.

Reasoning by analogy is a natural process that contrasts with Bajesten and statistical decision mode1s, which are hard to apply to most operational contexts. There is wuch current research. Into the importance of metaphor and analogs in creative thinking and decision making (Hoffman, 1980). Klein Associates has focused on the way experts use analogies to wake inferences and decisions (Rlein, 1985). We have studied liaster chess piajers (Rlein \& Peio, 1982), experts in cardio-pulmonary resuscitation (Klein \& Rlein, 1981), and are currently working with firefighting chiefs.

A corron exanple of this use of enalog! comes from real estate. A reeltor sets a spice for a property, not by using a formal model and calculating all the variables, but by choosing a conprable sale and adjusting its price on the basis of differences between the two properties. Engineers have traditionally wade use of analogies in prediction and design. The? typicalis look for structural comparison. If their task is to predict how reliable a new piece of equiprent 18 going to be, engineers use historical data for a basis of estimate.

A soraalized version, called Comparability Analysis, is found in the Air Force (Tetwejer, 1976). Developed in 1971, it is a way of explicitls using historical data to predict equipment reliablilty for the purposes of spare parts purchesing, manpower need projections, downtime forecasts, etc. Working directly from dir Force maintenance data, the engineer identifies a craft comparable to the one being planned. The next step is to derive an adjustwent factor that reflects the differences between the conparison case and the new equipment. The third step is to present the rationale for the adjustment factor. Next 18 to collect the uperational date for the comparison system, showing how reliable that equipment has been under operational conditions. The last step is to adjust these historical data to Benerate a prediction.

In the decade since Comparability Analysis was developed, it has been applied in the Air Force to a variety of new aircraft. Each involved a variety of subsystems, so that hundreds of these studies have been conducted. Widenhouse and Romans (1977) 
collected evaluation data contrasting predictions with observed data. When we analyzed these data (Klein and Gordon, 1984) we found that for mean-time between fallures, the correlation between predicted and actual data was .76; for maintenance manhours per flying-hours, the correlation was .84 .

KIein Associates assessed the process of Comparability Anelysis (Klein \& Weitzenfeld, 1982) and presented an explanation of. the logic underlying the use of comparison ceses to derive predictions (Wieitzenfeld, 1984; Weitzenfeld \& KIein, 1982). We were interested in proving the method and in increasing its range of application bejond reliability and logistics. We studied three existing nodels of analogical reascanis, and found that nore seewed to reflect the important aspects of Comparability inalysis: choosing an appropriate analogous situation; assessing the difference between it and the situation under study; and deriving an inference (prediction) by adjusting data obtained from the analog.

We have suggested a model of analogical reasoning that emphasizes the role of causal factors (Rlein, 1982; Weitzerfeld, 1984). This model states that for Situation A there is a set of causal factors $(x, y, z .$.$) that will determine or influence T(A)$, the target characteristic of $A$ to be estimated. Situition $A$ could be a new aircraft duct system; causal factors. $\therefore, y$, and 2 could be the size of the aircraft, the material used, and a particular construction technique; and $T(A)$ could be the reliability of the system as measured by Mean Time Between Failures.

In determining the target value, $T(A)$, we usually cannot Identify all of the causal factors involved, their effects and interactions. Instead, an analogous situation or conparison case (Situation B, another duct systen) is identified which reflects the same determinants as the target case. That is, for aircraft $B$, the same causal factors ( $x, y, z .$.$) determine a corresponding$ value, $I(B)$, as a measure of system $B$.

Although the same causal factors affect both $T(A)$ and $T(B)$, it is unlikely that the values of the causal factors will be the.. same in both cases. In using $T(B)$ as an estimate of $T(A)$ we can take note of the differences in the values of each of the causal factors and make adjustments in our predictions to take these differences into account. Although checklists of causal factors can be provided, the method requires experts to use their experience in identifying the most important causal factors to use.

Cowparison-Based Prediction is the methodology following from this model. The general CBP strategy (outlined in Table A1) begins with the definition of the target variable, T, and the identification of major determining (causal) factors known to affect it. Next a selection of possible comparison cases is identified.

From these, Subject Matter Experts (SMEs) choose one case, 
based on the similarity of the effect of tive causal factors between it and the target case. The comparison case value that is analogous to the target case value $T(A)$ is specified as $T(B)$. SNEs then make a rough estimate of the differences expected beween $T(B)$ and $T(A)$, most often only a judgment of whether $T(A)$ will be greater or less than $T(B)$.

Table A:1

The CBP Method

\begin{tabular}{|c|c|c|}
\hline Setting up the Problem & - & $\begin{array}{l}\text { Defining the Problen in } \\
\text { concrete terms: } T(A)= \\
\text { the Prediction Target } \\
\text { Framing the questions: } \\
\text { the Causal Factors and } \\
\text { Prediction Scenario }\end{array}$ \\
\hline Selecting the Resources & - & $\begin{array}{l}\text { Choosing the Comparison } \\
\text { Case and T(B) data } \\
\text { Choosing the SME(8)- } \\
\text { Subject Matter Experts }\end{array}$ \\
\hline $\begin{array}{c}\text { Collecting and Anelyzing } \\
\text { the Data }\end{array}$ & - & $\begin{array}{l}\text { Interviewing the SME(s) } \\
\text { Analyzing Causal Factors } \\
\text { to obtain } T(A) \text { from } T(B)\end{array}$ \\
\hline Documenting the Process & - & $\begin{array}{l}\text { Recording the Process } \\
\text { Leaving an Audit Trail } \\
\text { for others to Eollow }\end{array}$ \\
\hline
\end{tabular}

They then are guijed through an examination of the effect of the expected differences in values of causal factors, until this effect can be quantified so as to produce an applicable adjustwent factor figure. This factor is then applied to operational data for $T(B)$, to yield a prediction for $T(A)$. Analysis of the differences among factors produced by SMEs can produce a confidence range for the prediction. The process 18 documented to provide an audit trail, so that the basis for the prediction can be understood and the findings adjusted should changes ba made in the target case.

The CBP techniquie relies on the use of Subject Matter Experts (SMEs) who are knowledgeable about the dowain of interest, In order to select optimal comperison cases and Identify the relevant causal factors. The CBP approach elfelts SWE judgments through the use of a carefully structured interview with a format reflecting the CBP process outlined in Table A-l. The approach is data driven since the SMEs are generating 
adjustment of operational data and giving their reasons for making these adjustments. There may be cases where no operationa? data are available. It is possible to proceed with a CBP approach by having the SMEs estimate the operational data, but this is not the ideal application of CBP nethod, and. will reduce confidence in the outputs. However, this is often the state of affairs for the predictions where CBP is used, since this is usually the clearest case where there are no alternative prediction wethods.

An important element in the CBP strategy that can increase our confidence in the prediction is the development of an audit trail. The audit trail consists of a detailed description of the causal factors considered by the SHE, and the impact estimated for each. By having an explicit set cf causal factors to consider in determining adjustments, the SME has a set of concepts to use in posing the differences between the target case and the corparison case(s). This facilitates communication among SMEs and helps to standardize the variables considered in the prediction process. In addition, if the prediction is found to be inaccurate once operational data are obtained for the target case, the audit trail provides an opportunity to go back and see which considerations (causal factors) were responsible for the misjudgment. This process is obviously not possible winen only an unstructured expert opinion has been obtained.

It can be seen that CBP has several advantages over traditional prediction techniques. The CBP strategy is relatively easy and straight-forward, and can be used even when there are unknown parameters, missing data, or unclear objectives. In addition, it requires relative judgments from the SYE (evaluating one siturtion in relation to another), which seew easier for them to make than absolute judgments. Perhaps the wost important strength of the wethod is that it grounds the predictions in concrete experiences. Additionally, CBP creates an audit trail of the prediction process, which can later be used to evaluate and ioprove the prediction. Finally, it has high face validity in that it seems to be a structured form of a naturally: occurring inference process, ressoning by analogy.

How does this method compare with the traditional use of expert judgments? CBP does use expert judgment, but in a structured, definable, and traceable manner. This allowe for a clear and explicit basis to all judgments. The structure and definition are created by asking the Subject Matter Experts (SMEs) to identify relevant comparison cases and to make pairwise comparisons and relative judgments. For example, CBP would direct the SMEs to select those training devices that they are familiar with that are wost like the to-be-developed training device, in terns of major causal variables. By asking the SHE whether the new trainiag device is likely to be more or less complex (e.8:i type of technology, or nubber of tasks to be trained) or different in availability (e.8., one-per-class vs. one-per-trainee), CBP structures the process of estimating effectiveness so that better judgments can be cade. In contrast, 
asking Subject. Natter Experts to estirate the effectiveness of a new training device, without the benefit of CBP methods, can result in judgments based in a vide variety of approaches and experience that mas be more or less valid and comparable.

One brief validation study has been conducted to date. CBP was used to predict the outcome of an experiment on differences in effectiveness of functional and physical fidelity of training devices. Correlation of CBP predictions with test results was .90 , accounting for $81 \%$ of the variance.

A major limitation of Comparison-Besed Prediction is that it requires data about specific cases, not merely statistics about groups of cases. This date base is not alweys available but can usually be estimated setisfactorily by SMEs. This limitation can, however, also be viewed as an advantage: it combines 'real world' deta with expert judgment, and this ccrabination may. produce wore accurate estimates. The CBP methodology utilizes the skills and experiences of the SMEs for this purpose.

A prediction technique should be able to use most of the information avallable, such as causal relationships, and introduce few additional limitations or distortions. CBP fares well on these criterie. The following cautionary limitations of any prediction technique should be noted:

A. Requirement of expertise. Expertise is needed to describe the causal relationships, to identify comparison cases, and to plan and execute strategy in using coxparisons. Inexpert application can wake any technique ineffective.

B. Vulnerability to unknown effects. If a variable is net known to be influential, it cannot be taken into consideration. This is true of all predictive methods. CBP has the advantage of taking into consideration varlables whose relevance 18 unclear. since such variables are already eubedded in the comparison case dete.

C. Incomplete data. In practical predictive stuations resources are normaliy limited. Inadequate data and erroneous dote will degrade anj predictive process. One partial check for erroneous data is the use of redundancy. CBP has the potential for aploying various combinations of analyads and correction to Improve reliability. Moreovar it calls attention to the stmplifying sssumptions made in the absence of complete data, and trade-offs between effort and validity should becowe apparent. 
APPEXDIX B

SARPLE FORM 1

Menu: Possible Comparison Cases

Target

Device

1. $X x x$

2. $X X X$

3. $x \times x$

Comparison
Ceses

la $X \times x$

$16 \times x \times$

ic $x \times x$

$28 \times \times X$

$2 b \times x \times$

$2 c \times x \times$

3a $x \times x$

$3 b \times \times \times$

3c $\times \times \times$
Relevant

Feetures

- -

$\overline{-}-\overline{-}$

$--$

- -

$\therefore--$

$--$

$\overline{-}-$
Where

In Use

- -

- -

$-$

- -

- -

$-\cdot$

- -

- -

$-\cdot$ 
APFENDIX B:

SAPLE FORY 2

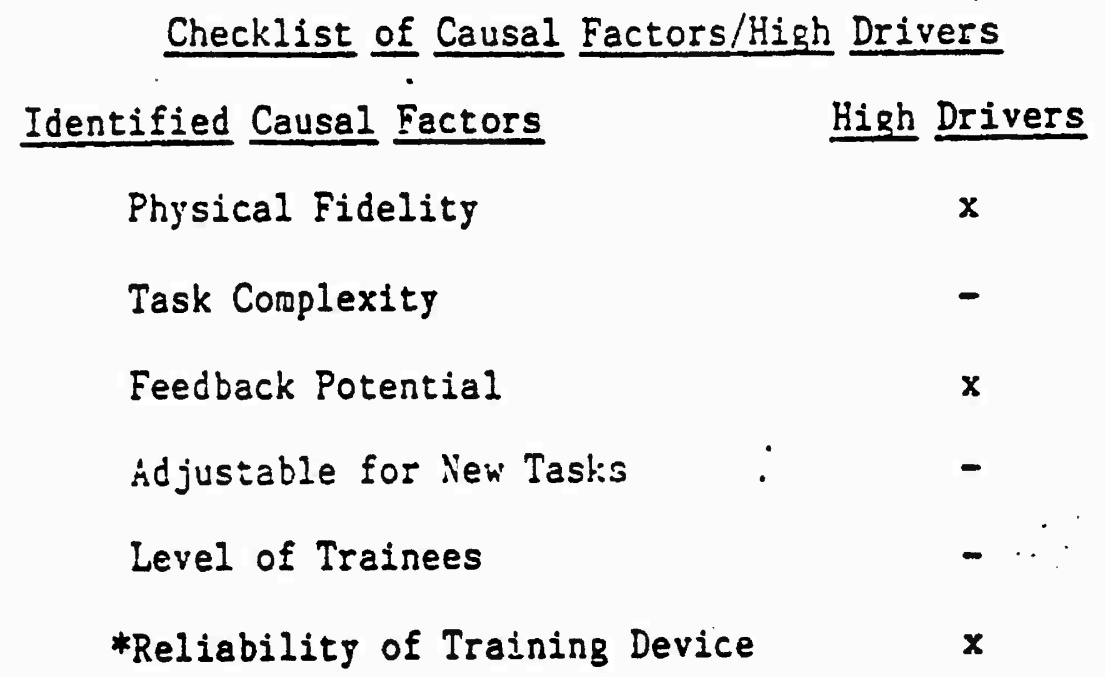

*added by S:E 


\section{Interview Guide/Data Sheet}

Step 1 Introduce task.

Step 2 Describe A.

Step 3 Determine B.

Step 4 Identify high drivers.

Step 5 Establish $T(B)$.

Step 6 Judge global $T(B)-T(A)$ differences.

Step 7 Specify $T(B)$ adjustment and predict $T(A)$.

1. DATE

2. SME \#

3. NASE

4. IELEPHONE

5. HOK REACH LATER

****[Introduce Self]

6. JOB

7. Length of Experience: in Job

with TD (B)

STEP 1 
10. Describe A. Present Checklist of Causal Factors/Hiah Drivers and record answers to 13 and 14 here.

High Drivers

$T(A): \pm$ or $=? \quad$ Absolute or $\%$

Physical Fidelity

Feedback Potential

Task Complexity

Adjustable for Nien Tasks

Level of Trainees

Other:

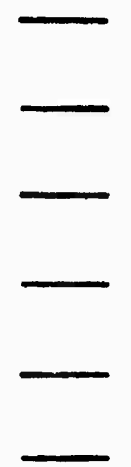

11. Ask if there are additional causal factors to be considered (add above).

STEP 5

12. Review $\mathrm{T}$ : What is the value of $\mathrm{T}(\mathrm{B})$ in your experience?

STEP 6

13. For each, ask SME to judge direction of difference (+ or -) for $T(h)$. (Record in 10 above.)

STEP 7

14. Ask if can estimate degree of difference for $T(A)$ on each causal factor. (Record in 10 above.).

15. Adjust $T(B)$ to $T(A)$ on basis of above.

16. This is geur prediction -

Are you comfortable? Any. Changes?

Any Provisos? 
AFPENDIX B:

SAPLE FORY 4

\section{Documentation}

The documentation of a CBP application usuaily takes the form of a brief written report. The checklists and other interview forms are attached and referenced. If multiple SMEs and/or comparison cases have been used, the data are presented ir tables.

The briefest documentation could take the following form:

1. Froblen:

2. Prediction Obtained: $T(A)$ :

Discussion of meaning of $T(A)$

S:EEs comments on TD design, training implications, etc.

3. Summary of CBP Process:

SiE background data

Menu of comparison cases showing those considered and those used

Checklist of causal factors showing those use, not used, and added by SMEs

Interview form

Table of SME judgments on effect of each causal factor

Table or figure showing calculations of $T(A)$ and confidence ranges.

Listing of S:IE compents that have relevance for TD design or training program. 


\section{APPEIDIẌ C: THREE CASE STUDIES}

[NOTE: These three case studies are excerpted from research undertaken for the Army Research Institute, assessing the feasibility of the CBP methodology for problems of predicting training device cost and effectiveness. You are encouraged to read the full reports of these studies for a more detailed presentation of the development of each CBP element and the application of the method.]

\section{CASE I: The High Driver Strategr}

In this instance, an automotive maintenance instructor was asked to predict the time that might be saved in his course if a training device, the Army Maintenance Trainer Evaluation Study (AMTESS), were available for class use. The following elements of CBP strategy were already decided upon in preparation:

- The target value $T(A)$ was determined to be minutes saved in Course 63 W10 if the AMTESS was used.

- The comparison case was chosen to be the course as taught currently, winch used the actual automotive equiprent (AET) for instrucion.

- Five causal factors were identif'.ed.

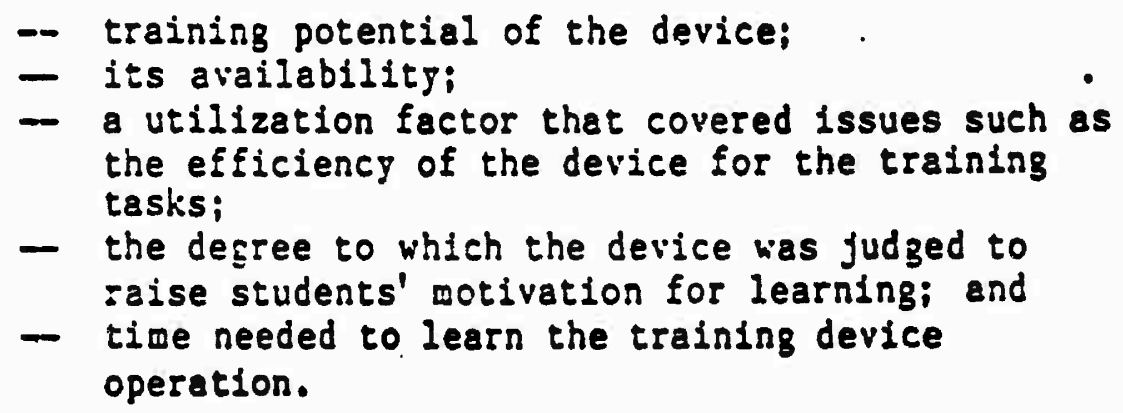

The SME was asked to consider the target variable $T(A)$ : minutes saved in training for trouble-shooting of the engine starting system. He first estimated the number of minutes that were now spent in teaching this task to criterion, using only the actual equipment for instruction and practice. This judgrent produced the comparison case measure $T(B)$.

He was then asked to consider the effect on $T(B)$ that using the training device would have. The SME was not asked to rake this judgment in one step. He was asked first to make a global judgwent: if using the training device would increase, or decrease, or leave unchanged the number of minutes needed to train this task to criterion? Then he was asked to consider, one 
at a time, the five causal factors identified as driving considerations in this judgment. He then determined an adjustment to the total time based on each factor.

When asked to consider the effect that the first causal factortraining potential of the training device--would have on training time for this task, (training for engine-starting troubleshooting) the SME was led through the method as follows:

1) How mang minutes are used for training this task as the course is now constituted?

2) Consider using the AMTESS training device in this course instead of the actual vehicle. As you juige the training potential of the AMTESS training device compared to that of the venicle itself, would using the AMTESS training device produce a savings of time in the course? Or would it require additional tiwe to teach the task? Or would it make no difference in the time needed to teach this task to criterion? Express jour answer in actual minutes saved or added.

3) If using only the AMTESS training device and not the vehicle itself means you cannot train to criterion, you can consider using the AMTESS training device with some supplementary training on the actual vehicle. How much time woulc that add to your estimate?

4) Now consider the factor of availability. Knowing what you do about the way the AMTESS training device availability compares to the actual vehicle, would using the AriTESS training device save or lose time in the training for this task?

The S.:E was led through this procedure for each of the remaining three causal factors: utilization, motivation, and training device learning time. With each, $T(B)$ was adjusted for the first teaching task. The procedure was repeated for other tasks within the course, such as training the trouble-shooting for an oll pump Eailure. His answers on each factor were sunned, and adjed to $T(B)$ to gield $T(A)$, a prediction of the nusber of winutes it would take to teach this course if the A:IESS training device were used. The SME's estimate for each causal factor was a xeasure of time saved (or added) in the course.

Comparison of $T(B)$ with $T(A)$ showed a net savings on this task of $17 \%$ of training time if the AMTESS training device was used, supplemented by actual equipment. The major adjustwent that led to the savings was on the factor of motivation. The SME thought that the training device was designed so that students would participate in the class to a degree that would ave considerable training time. The table below represents an "audit trail," an elewent of the CBP wethod which assures that the prediction can be examined. 


\section{HIGH DRIVER STRETEGY: ResuItS}

Course Time Savings Prediction: AMTESS training device Prototype, Course 63\%10 [Estimate of $T(B) *$ current total course time $=450$ minutes]

$\begin{array}{lc}\quad \text { CAUSAL FACTOR } & \text { MINUTES SAVED } \\ \text { Training Potential } & -30 \\ \text { Availability } & 30 \\ \text { Utilization } & 0 \\ \text { Motivation } & 100 \\ \begin{array}{l}\text { Training Device } \\ \text { Learning Time } \\ \text { OVERALL SAVINGS }\end{array} & -\frac{-25}{75} / 450=17 \%\end{array}$

*The Actual Equipment is the comparison device, used in 63 wio

Other forms from the AMTESS study are attached (Figures $C: 1$ $\mathrm{C}: 4)$, to show you the variety the CBP method produces. Remember, CSP is an approach, with besic elements that you are to apply to your own situation. Start with these elements and design your own forms to hold the information you need. 
GRUMMAN

1. Principle of Simulation

2. Ceneral configuration

3. Instructor station

i. Student stations

5. Ciaphic display

5. Alphanumeric

7. Input device

3. Keyboard

?. Test equipment

10. 30 hardware .

11. Cperating System

12. Program storage

13. Program language

¿. iutroring system

15. Portaoility

16. Interfaces

17. Modularity

18. Diagnostics

19. Repair procedure

20. Motion

21. Audio

22. Fault insertion

23. Hotor skills training

24. Actual equipment
Simulated, generic

Independent student control station

Same as student station

Single-student :

Color CRT video dise

17" tube

BW CRT 12"

Touch panel (finger)

Required for instructor only

Actual measurements simulated T.E.

Family generic, contertpreserved

Pascal, fixed P州. convertible to $i \mathrm{OA}$

Floppy dise

Pascal (convertible to ADA: Instructor-easi:: used High

20-30, seleciatle to

110K baud printer

Cood

To individual module

Substitution of modules

full-plus freeze

Full

Simulated, program mediated

Via 30 simulation hardware Not required but usable
SEYILLE

Simulated. actual (models:

Satellite, instructor mediated

Sefarate instructor station Single-Student

Slide Projector Screen \& CR?

CRT BW

Function keys on response panel

Required of instructor only

Hctual measurements simulated T.E.

Family, models, contex:preserved

RT-1] DEC

Winchester Disc $w / f l o p p y$ backup

iRIC (Eurtek proprietary:

Instructor, medium diffisul::

ileoium

Printer R.S-232 9600 saud

Hedium

Test program, diagnostics for compute:

Vone specified-from T.M.

None

None on radar, engine sounds on diesel

Simulated, instructor mediated

Hodel of actual equipment iot required not usable

- Context is that of a diesel powerplant C-4 


\section{Figure \\ $c: 2$}

Course lasks Used in Predicting Training Effectiveness

Grumman

6.3030 and $63 \mathrm{H} 30$
iask 1: Perform tests on electicical system icontinuity test with STE'ILE, resistance test with SiE:ICE. DC loltage test with STE 'ICE. AC loltage test with Si: !CE

Task 2: Troubleshoot electrica: sỵstem (starting systen. generating system, tatte:y power system)

Sevilleigurtek

$63: 110$

Task 1: Troubleshoot engine starting :vistem

lask 2: Troubleshoot oil pliff ialluse organizaional and direct support?

- Perform organizational trcubleshooting

- Perform direct suppcrt troubleshooting

- RiR oil pump filter and oil pump

E3E30

Task 1: Troubleshoot oil pumo fajlure (organjzational T/S ondy.

Task 2: idjust alternator drive bel:

iesk 3: R.'R starter metor

lask 4: Inspect electrical suspen Copr avaliahle to DMC doen nde
persitit $1: 1:$ 
Summary of SME Background

Maintenance

Course Instructors

SME 1

SME 2

SMIE 3

51454

SIME 5

Air Force 6883 215

SME 6

SliE 7

SME 8

Prototype TD Evaluators

SME 9

S:AE 10

Location
APG
APG
Edgewood
Arsenal
Edgewood
Arsenal
Edgewood
Arsenal
Air Force Human
Resources
Laboratory

Honeywe11

Honeywell

APG

Ft. Bliss
Area of Expertise

Course 63030

Course $63 \mathrm{H} 30$

Course $63 w 10$

Course 63830

Course 63830

Evaluation of Honeyivell 3-0 and Burtek 2-D simulators

Design Engineer

Research Psychologist

Evaluated To for automotive tasks

Evaluated TO Eor nissile tasks 
CEP Forms, ANIESS

Name

Office Symbol and Telephone

Date

Course Taught

\# Students

Course Length $A_{t}:$

AHIESS device:

Task:

Esmparison device(s): $B_{t}:$

Target Configuration:

Relative Impact: Target Configuration vs. Existing Configuration: Better Seme Worse

Causal Checklist:

i=aining Potential

(Procedures.

Perceptual-11otor, Decision making, Tes' Integration, Jiner

Itilization

Iricegration into PUI, Ease of CEËatjisn. SEtUp time, Performance Evaluation, Instructor Aids, Ease of Modification)

Avajlability (Reliability, Supportability, Repairability)

Motivation

Other

Totel

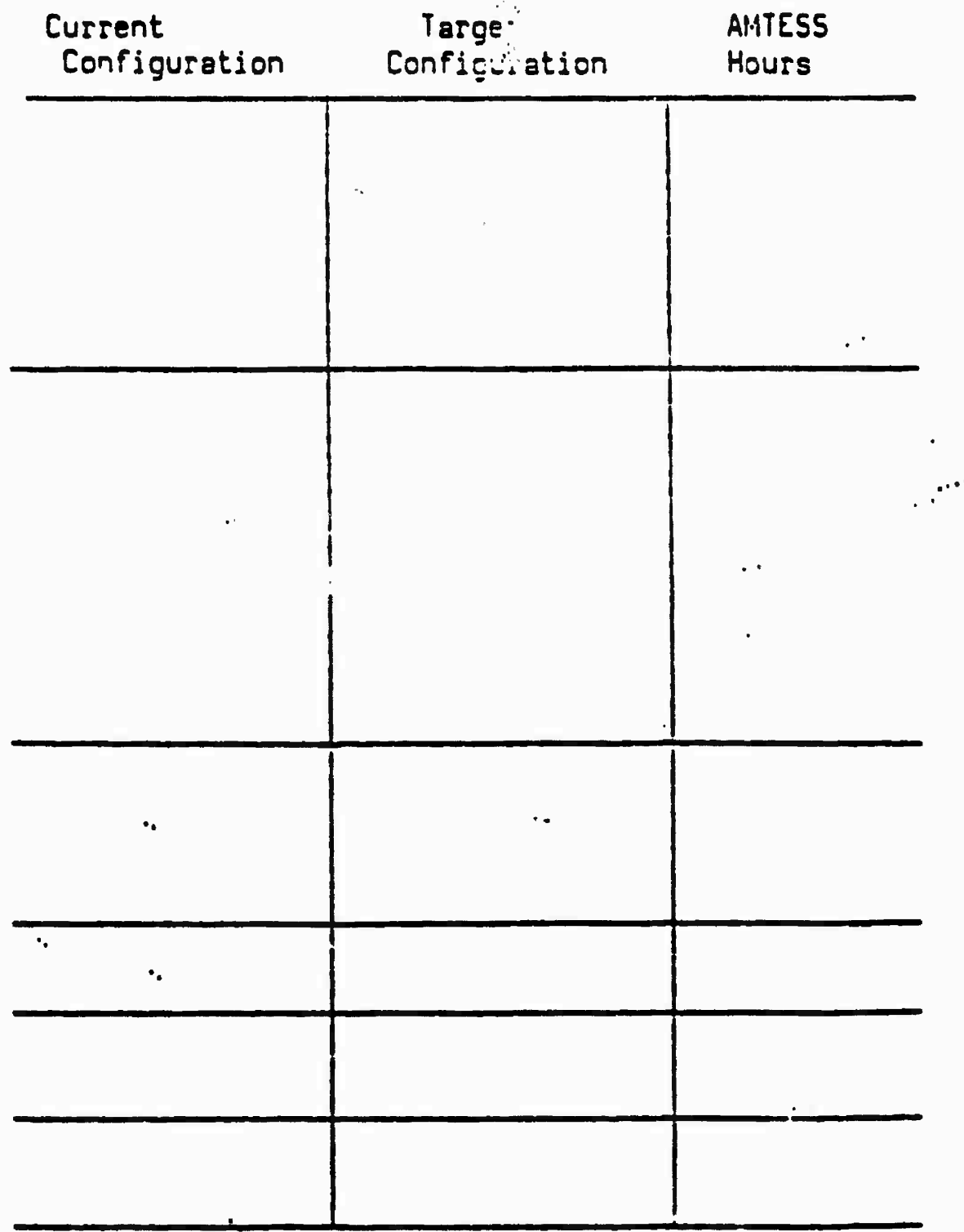


SME Judgment of

Potential Impact of Causal Factors

on Training Time

Causal Factors

Training Time*

(1)

Student

learns to

use TD
(2)

Irain rask

on

Ti)
(3)

Supplemental

Irrining on AEI

(A) 0:iginal Set (Prepared before interview):

Iraining Potential

Utilizetion

Availability

Yotivation

+
+
+

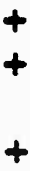

(B) Alernative Detailed Set (Developed in interview):

Iraining Potentisl

TD provides accurate feedbrak

TD teaches use of the Technical Manual

ID shows where components are on the AET

Ltilizacion

Ease of programming malfunct Ions

TD allows skipping of steps

Computer response time

Avaliability

Rellability

Ease of mainetnance

TIme required for maintenance cacks

General

Difficulty of learning to use TD

Information proyided by manufacturer

Use of videodise

Requires reading skills

*aseline 18 current course ting. + Indleates estinated addition to this tina because of ID use.

(1) Iles needed to leara to use TD Itself.

(2) TLe needed to traln task on TD.

(3) Itse needed for suppleecatel tralning on Actual Equipeeat.

$$
\text { C- } 8
$$


In this example, a tank gunnery instructor (SME) was asked to predict the effectiveness of a tank gunnery training device Videodisc Gunnery Simulator (VIGS). The scenario provided hit was to assume that the men were to practice on the VIGS during the $s i x$ months between their. school gunnery training and their first unit field exercises. The following elements of the CBP strategg were determined:

- The target value $T(A)$ was defined as number of first-round hits on Gunnery Tables VI and VII.

- Multiple comparison cases were chosen from among training devices that are used in gunnery training classes.

- Multiple causal factors were identified in advance but the SME was to choose his own besis for comparison during the prediction process itself.

The SME was asked to consider the number of first-round hits the gunner would attain at the end of training. He then judged the number of first-round hits he would attain six sonths later with no intervening training or practice. This lattis judgment would be a first, beseline $T(B)$. Then he also est:tited the performance of the best gunner imaginable six months after school training, to set an upper prediction lialt.

The SME then was asked to consider, one at a time, other training device's, and to estimate the number of first-round hits the gunne: wight achieve six wonths after training if that training device had been used for practice for a specified period in the six wonth interval. These judgments ylelded additional $T(B) s$ (see 111ustration).

With these figures for comparison, the SME then predicted the aumber of first-round hits likely if the gunner tratned on the "IUS device for the specifled period in the six wonth interval: This figure was $T(A)$. The difeerences between $T(A)$.. and the $T(B) s$ was a measure of the reletive effectiveness of the VICS device (80\%-72\%, for example, for VIGS relative to "no practice").

One effect of the use of different comparison ceses was to structure the prediction spece that the SME used. By sotting upper and lower limits, the total space was bounded... By positioning the different comparison training devices within that space, the locus of the target training device was pore clearly defined.

In this Instance, the SME, was able to predict training device effectiveness under two test conditions (moviag and stationary platforas) and for two tank environaents (M6O/A1 and M6O/A3). Whan the predictlows of several SMEs were compared, they coaverged closely on the sane $T(A)$. 
MULTIPLE CONPARISON STRATEGY: Results

Gunnery Training Effectiveness Prediction, VIGS Trainitig Device

\author{
CEILING: $92 \pi^{\prime}$ \\ (Estirated, \\ best gunner, \\ no practice)
}

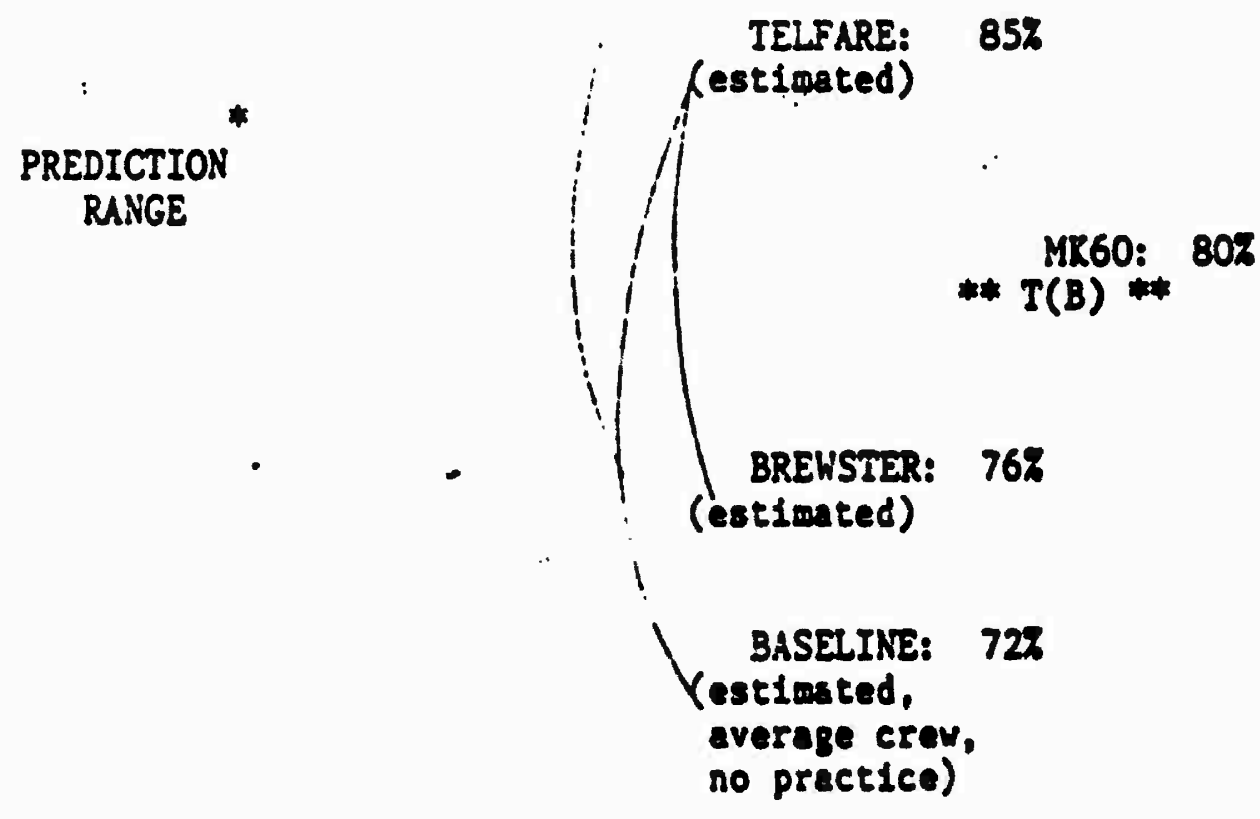

$*$

PREDICTION expressed as percentage of first-round hits attained six monthe after school training, at start of first unit fleld exercise

Other fores relative to the VIGS study are appeadad (FIgures C:5 - C:9 Again, they raflect the application of CBP to this particular probles. They 1llustrate the flexibility of the bethod, and the way its elesents can be adapted to differeat needs. 
The Prediction Scenario: End-of-training Proficiency and Sustainment Proficiency

Iotability ff firstfound hits.

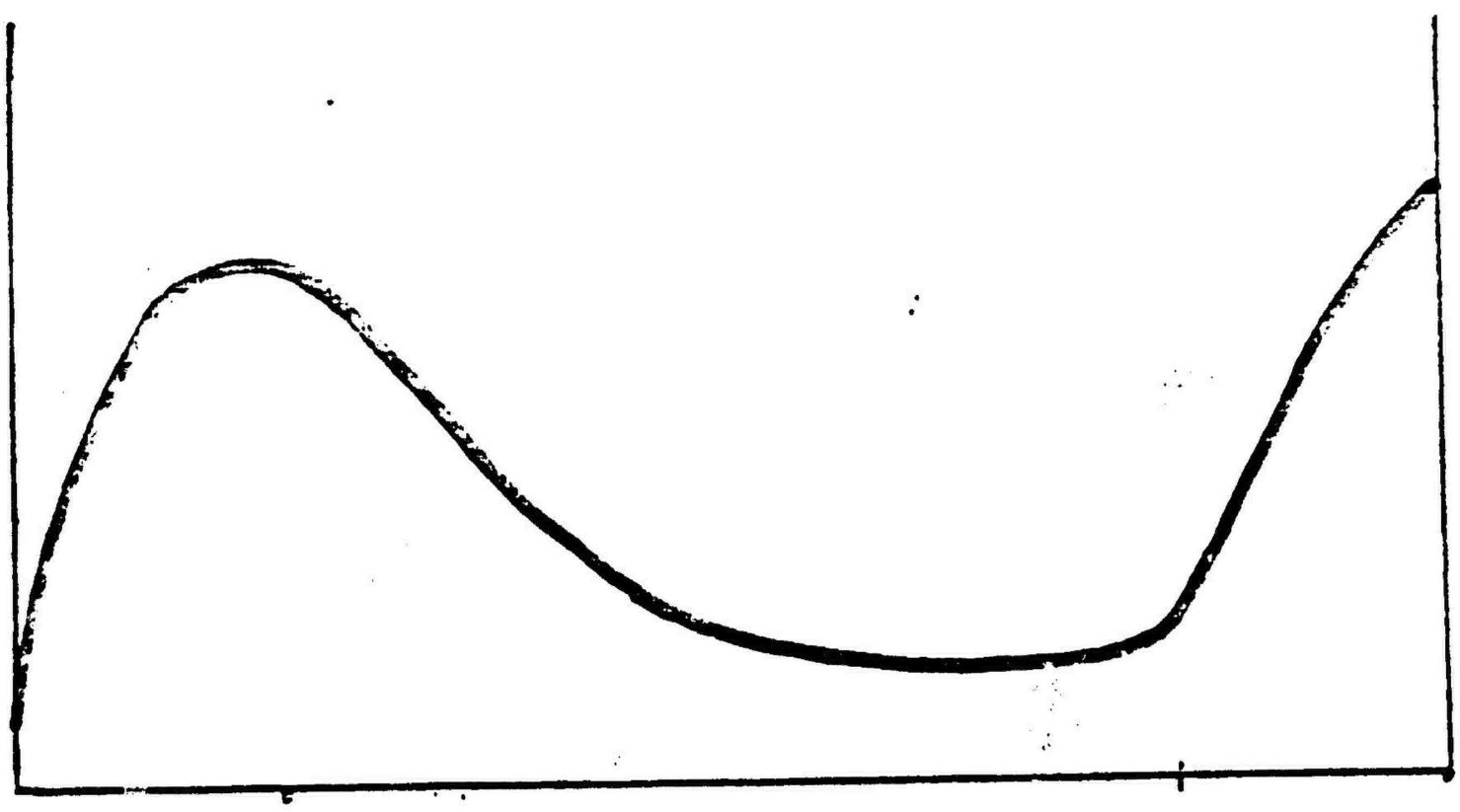

$P(1)$

Training

Period

6-months elasped time

RE-TEST

Period

$P^{\prime}$.1) Estimate of : first-round hits when proficient at end of initial trasning P:z; Estimate of : first-sound hits on Tab!s $! l$ and VIl after 6-manth iriterva! 
1. The Telfare TD (TEL)

This device is tank-mounted, and includes a bracket which permits the use of the 1.2 .50 cal machine gun (in single shot mode) in lieu of the main gun. It can be fired against full-size targets with a curtailed range or against half-size targets, half range. All four tark crew members can practice coordination for both stationary and moving platform gunnery. The range finder can be used, including LRF, but there is no range correction for the half range mode. The device can be used with thermal sighting as well as the standard optical sighting. Laying the sight on target, tracking. firing, and fire adjustment can be practiced.

2. The Brewster TO (BRil)

This device is also tank mounted, and includes brackets permitting attachment of small caliber weapons (either .22 cai or $5.56 \mathrm{~mm}$.). It is used only with stationary platform gunnery tasks. In the .22 cal version, a minified range ( $1 / 30$ or $1 / 60$ scale) is used with very small targets on a sand table (stationary and moving targets). Sight laying, tracking, firing, and fire adjustment can be practiced as well as overall.crew coordination.

3. The Tank Gunnerv and Missile Tracking Svstem TO (TCMTS)

This device is mounted on a tank, but used inside a large indoor training facility. It includes a rear-projection screen depicting the battlefield, and a laser device.mounted on the tank turret to simulate the main gun firing. It is used to train both $T C$ and gunner to gain coordination and efficiency. . Feedback can be provided to the gunner in the form of "frozen" action shots to show "the exact point of hit. Tasks trained include stationary and moving targets, but only from a stationary platform.

4. Actual Equioment Treiner (AET)

As a final comparison case, some SMEs were asked to generate predictions based on comparison with the use of an actual tank with the firing of real main gun ammunition. In some ways this can be seen as thie ideal training device. However, there are certain drawbacks to using the AET for training. such as cost, range availability, a lack of feedback, etc. 
SME Background Information

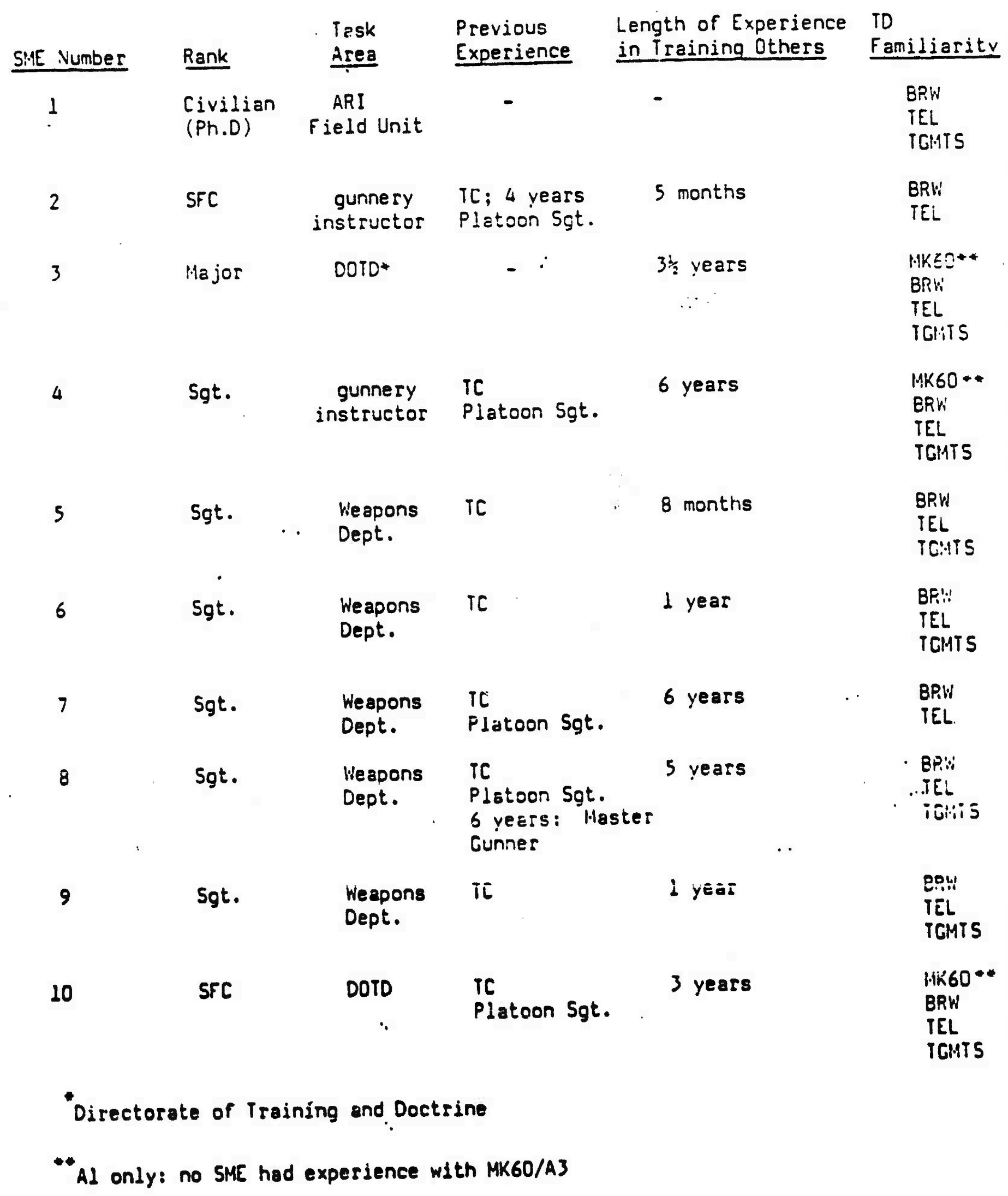




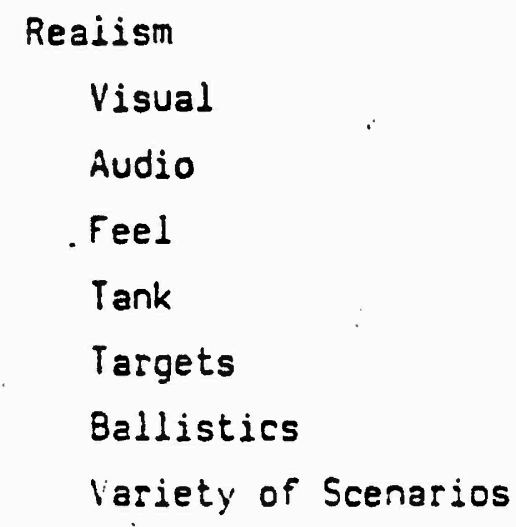

\section{Crew Coordination}

TC ranging practice

TC - gunner interaction

Loader - gunner interaction 
CASE III: Global Prediction Straterr for hcouisition Cost

This study applied the CBP methodology very early in the design process of the Howitzer Improvement Progran (HIP). The new system itself was not yet firmly described, so the new training requirements were unclear.

The prediction variable, $T$, chosen was

- Acquisition cost of a HIP training device.

Given the early stage of the design process, we were not sure how CBP would work. He found that it worked easily, because at this early stage, proposed devices were being identified on the basis of anaiog: to specific existing devices!

The procedure for proposing a device was largely that of identifying trainers for other systers and evaluating their utility for HIP.

Since tank gunnery training was going to be conducted in a new Conduct of Fire Trainer (COFT), one proposed HIP device was analogous to COFT. The question for us was: what would it cost? To answer this, we obviously used the COFT as the comparison. There were two versions: ICOFT (an institutional trei-ier) and UCOFT (a unit trainer). Since HIP would need an in; -itutional training ievice, we selected ICOFT.

The SME chosen was in the Armor Division at PM TRADE. He had been involved in the development of ICOFT and the evaluation of UCOFT, and had 13 years Army experience.

He broke the definition of $T$ into separate components for building, hardware, and RDT\&E (research, development, training, and evaluation) which includes the development of instructional software. Next, he listed the high drivers nost likely to affect the differences between the cases, for each of these corponents.

iie judged that the factors likely to have eust iapact on building costs were heating, air conditioning, computer support equipment,. and power distribution. For hardware cosss he considered ildeilty of the simulation, mechanical requirements for spasifle new tasks, the computer system size, the visual system, and the number of stations needed because of different student/teacher ratios that could be sustained. RDT\&E costs would differ between the two system: wuch of the development of the old system would carry over for the new and did not need duplication; there would not be competitive procurement; reducing cost; and simpler software would be needed.

The SME was asked to make global adjustments to UCOFT costs for which he supplied figures w- in order to predict costs for the HIP device. Since he could judge the number of stations that would be required, he was asked to estimate the cost of a single station and then multiply by the nubber required to reach a total 
cost. The resilts are as follows:

\begin{tabular}{|c|c|c|}
\hline Factor & $\begin{array}{c}\text { COIPARISOII CASE } \\
\text { ICOFT }\end{array}$ & $\begin{array}{l}\text { HIP } \\
\text { PREDICTION . }\end{array}$ \\
\hline Building & $\$ 4,750,000$ & $\$ 2,500,000^{*}$ \\
\hline Hardware & $3,600,000$ & $8,000,000 * *$ \\
\hline RDT\&E & $5,300,000$ & $8,000,000 * * *$ \\
\hline & $\$ 13,050,000$ & $\$ 18,500,000$ \\
\hline
\end{tabular}

* Primary reason for difference: 16 student stations for proposed HIP device vs. 36 for ICOFT. This impacts air conditioning, heating, computer support equipment, power distribution.

** The HIP recoil mechanist will be very costly. On the other hand, the visual requirements for HIP will be less, as will the computer requirements, since HIP doesn't need to compute round trajectory in real time. Another factor fevoring HIP is the ratio of 1 instructor station/4 student sations; it is $1: 1$ sor ICOFT.

*** The ICOFT benefitted from \$33M spent on RDT\&E for UCOFT. The total COFT expenditure was $\$ 38.3 \mathrm{M}$. The total for HIP is therefore much less than the total for COFT. The reasons are: the COFT project included an expensive competition between GE and $G D$, the howitzer problems are simpler - no lead or trajectory concerns, fewer dynamics. The howitzer expense for turret recoil should be breater.

This process produced a clear audit trail, including documentation of the assumptions the SME made in his prediction, the comparison case on which $1 t$ was based, what types of adjustments were made, and the factors that were considered in making them. This estimate can thus be revised ae more factors become known. It can also be compared to estimates mede by other means. 